\title{
Cochlear Implant Data Logs Predict Children's Receptive Vocabulary
}

Tobias Busch

KU Leuven and Cochlear Technology Centre

Anneke Vermeulen

Pento Audiological Centres and Radboud UMC Nijmegen

Margreet Langereis

Pento Audiological Centres and Radboud UMC Nijmegen

Filiep Vanpoucke

Cochlear Technology Centre

and Astrid van Wieringen

KU Leuven

Author Note

Tobias Busch and Astrid van Wieringen, KU Leuven, Department of Neuroscience, Research Group Experimental ORL, Leuven, Belgium; Tobias Busch and Filiep Vanpoucke, Cochlear Technology Centre, Mechelen, Belgium; Margreet Langereis and Anneke Vermeulen, Pento Audiological Centres, The Netherlands and Department of Otorhinolaryngology, Head and Neck Surgery, Hearing and Implants, Radboud University Medical Center, Nijmegen, The Netherlands Conflicts of Interest and Sources of Funding: This study was supported by the FP7 people programme (Marie Curie Actions), REA grant agreement FP7-607139 (iCARE). Tobias Busch has pursued a PhD at the KU Leuven. He was funded jointly by the European international training network iCARE and by Cochlear, the manufacturer of the cochlear implant system used in this study. Filiep Vanpoucke is also an employee of Cochlear. For the remaining authors, none were declared.

Correspondence concerning this article should be addressed to Tobias Busch, University of Oslo, Department of Special Needs Education, Postboks 1140 Blindern, 0318 Oslo. E-mail: tobias.busch@isp.uio.no 
Abstract

2 Objectives. The data logs of Cochlear ${ }^{\mathrm{TM}}$ Nucleus ${ }^{\circledR}$ cochlear implant (CI) sound processors

3 show large interindividual variation in children's daily CI use and auditory environments.

$4 \quad$ This study explored whether these differences are associated with differences in the

5 receptive vocabulary of young implanted children.

6 Design. Data of 52 prelingually deaf children, who had received a CI before three years of

7 age, were obtained from their clinical records. In total, 73 Peabody Picture Vocabulary

8 Tests (PPVT) and CI data logs for one year preceding each test were collected. The data logs

9 were used to determine the children's average daily amount of CI use and exposure to

10 speech, speech in noise, noise, music, and quiet. Additionally, information was collected

11 about other potential predictors of language abilities, namely gender, age, age at

12 implantation, etiology of deafness, educational placement, and implantation mode

13 (unilateral, bilateral). Model selection with Akaike's information criterion was used to

14 determine which data-logging metrics, other variables, and combinations of both best

15 predict receptive vocabulary scores.

16 Results. The data showed a strong positive association between receptive vocabulary and

17 daily CI use, and a negative association between receptive vocabulary and daily exposure to

18 music. Associations with the data logs' speech and noise metrics were less clear. The most

19 important other variable was educational placement. The best model performance was

20 achieved when data logs and other information were combined.

21 Conclusions. The results emphasize the importance of consistent $\mathrm{CI}$ use and a rich

22 auditory environment for the early language development of young $\mathrm{CI}$ users. The study also 
1 shows that CI data logs capture information about children's environment and CI use that

2 are related to language performance and can help to detect and address problems and

3 improve their auditory rehabilitation. 
2 Worldwide, around 215,000 children with profound hearing loss (HL) use a cochlear

3 implant (CI) to access their auditory environment (Cochlear Ltd., 2017). These children can

4 achieve spoken language outcomes on par with their normal hearing (NH) peers, but their

5 performance scores show large interindividual variation, and not all children with CIs

6 reach age-adequate language levels (Kral, Kronenberger, Pisoni, \& O’Donoghue, 2016; van

7 Wieringen \& Wouters, 2015). Some variation in the performance of children who use a CI

8 or hearing aid (HA) can be explained by environmental factors (Houston et al., 2012;

9 Markman et al., 2011) such as socioeconomic status (SES; Geers et al. 2011; Le Normand \&

10 Moreno-Torres 2014), educational placement (Moog \& Geers, 2010; Sparreboom,

11 Langereis, Snik, \& Mylanus, 2015; Wie, Falkenberg, Tvete, \& Tomblin, 2007), family

12 composition (Geers et al., 2011; Macaulay \& Ford, 2013), communication mode (Boons et

13 al., 2012; Le Normand \& Moreno-Torres, 2014; Wie et al., 2007), parent-child interactions

14 (Holt, Beer, Kronenberger, \& Pisoni, 2013; Niparko et al., 2010; Quittner et al., 2013), or

15 linguistic input (Cruz, Quittner, Marker, DesJardin, \& the CDaCI Investigative Team, 2013;

16 DesJardin \& Eisenberg, 2007; VanDam, Ambrose, \& Moeller, 2012). To some extent, these

17 factors are reflected in children's daily auditory environment-for instance, the amount of

18 exposure to spoken language, or the presence of background noise.

19 CI users' auditory environment and CI use can be analyzed automatically with the

20 Cochlear ${ }^{\mathrm{TM}}$ Nucleus ${ }^{\circledR} 6$ CI sound processor (N6; Cochlear Ltd., Sydney, Australia). N6 keeps

21 a data log, in which it tracks — among other things—time spent in different auditory

22 environments (speech, speech in noise, noise, quiet, music, and wind), use of accessories 
1 like personal frequency modulation (FM) systems, and overall CI use (also known as time on air). To distinguish between auditory environments, N6 uses an auditory scene classifier

3 that has been trained through supervised machine learning-that is, using a database of

4 labeled recordings (Mauger, Warren, Knight, Goorevich, \& Nel, 2014). Knowing the user's

5 current auditory environment allows the sound processor to automatically optimize the

6 signal path, for example, by activating noise reduction in noisy environments or enabling

7 directional microphones when speech is presented in background noise. The data log is

8 stored on the sound processor and can be read out at the CI clinic (for more details see the

9 Methods section). Clinicians can use data logs to monitor CI users' daily auditory

10 environment and usage behavior between clinic visits. With pediatric CI patients, such

11 measurements might help to detect and address problems before they affect language

12 acquisition, social and cognitive development, or academic achievement (Ambrose,

13 VanDam, \& Moeller, 2014; Barker et al., 2009; Connor \& Zwolan, 2004; Holt et al., 2013).

14 Similar technology has long been available in hearing aids (Mueller, 2007). Moreover,

15 there are dedicated tools for automatic naturalistic measurements of the auditory

16 environment-perhaps the best-known of which is the Language Environment Analysis

17 system (LENA; Gilkerson et al., 2017). Researchers have used such methods to explore the

18 influence of the environment on language development (Ambrose et al., 2014; Gilkerson et

19 al., 2018; Walker, Holte, et al., 2015), and clinicians are using them for the fitting of hearing

20 devices, counseling, and intervention (Archbold et al., 2015; Leffel \& Suskind, 2013; A.

21 McMillan, Durai, \& Searchfield, 2017; Muñoz, Preston, \& Hicken, 2014; Suskind et al., 2016).

22 To determine whether N6 CI data logs can help improve the auditory rehabilitation of

23 children with $\mathrm{CI}$, it is crucial to understand how the captured information relates to 
1 rehabilitation outcomes. Regarding language development, three data logging metrics are

2 particularly interesting: daily CI use, exposure to spoken language, and exposure to noisy

3 environments.

\section{Daily CI Use}

5 Several studies have investigated the impact of hearing-device use on rehabilitation

6 outcomes-either through data logs or through subjective reports-and have found that

7 consistent hearing-device use is associated with better functional language outcomes and

8 language growth in children with a HA (Tomblin et al., 2015; Walker, Holte, et al., 2015)

9 and with better speech perception in children with CIs (Easwar, Sanfilippo, Papsin, \&

10 Gordon, 2018; Wie et al., 2007). One explanation for this is that hearing-device use creates

11 opportunities for language exposure and learning. Furthermore, low or inconsistent

12 hearing-device use might indicate trouble adjusting to the device or a lack of support, and

13 can foreshadow poor use or nonuse (Archbold, Nikolopoulos, \& Lloyd-Richmond, 2009).

14 Inconsistent use can also be related to the child's state (e.g., mood, fatigue, or illness;

15 Walker et al., 2013), frequent removal of the CI's magnetic coil (Easwar, Sanfilippo, Papsin,

16 \& Gordon, 2016), and caregivers struggling to manage the hearing device (Muñoz et al.,

17 2015) or monitoring its use (Walker, McCreery, et al., 2015; Walker et al., 2013).

18 The amount of CI use can be measured automatically and objectively with N6 data

19 logs. Busch et al. (2017), for example, analyzed N6 data logs of 510 children and found that it

20 increased from a median of $8.5 \mathrm{hrs} /$ day in the first 6 years of life to more than 11 hrs/day for

21 older children (Busch et al., 2017). The interindividual variation was considerable, with

22 interquartile ranges (IQRs) beyond $3 \mathrm{hrs} /$ day, and a difference of roughly $10 \mathrm{hrs} /$ day

23 between the top and bottom 5\% of the distribution in all age groups (Busch et al., 2017). 
1 Similar distributions of daily CI use were found in other large samples of N6 CI data logs

2 (Cristofari et al., 2017; Easwar et al., 2016, 2018; Oberhoffner et al., 2018; Wiseman \&

3 Warner-Czyz, 2018).

\section{Exposure to Spoken Language}

5 Child language development is driven by language input and facilitated by qualitative

6 aspects—such as child-directedness, linguistic scaffolding, and interactivity (Hoff, 2006;

7 Tamis-LeMonda, Kuchirko, \& Song, 2014; Zauche, Thul, Mahoney, \& Stapel-Wax, 2016).

8 Various studies have recorded and analyzed naturalistic parent-child interactions, and

9 some of them have used LENA to make comprehensive naturalistic measurements. Their

10 results indicate, that the language development of children with CIs is related to their

11 parents' mean length of utterance (MLU; DesJardin \& Eisenberg 2007), lexical diversity,

12 and use of facilitative language techniques (Cruz et al., 2013; DesJardin \& Eisenberg, 2007),

13 as well as maternal sensitivity and linguistic quality of parent-child interactions (Quittner

14 et al., 2013). To our knowledge, an association between the sheer quantity of language

15 input and language performance has not been observed for children with a CI, but for

16 children with NH and HAs (Hurtado, Marchman, \& Fernald, 2008; VanDam et al., 2012;

17 Weisleder \& Fernald, 2013).

18 Compared to their NH peers, children with CIs face additional challenges in language

19 learning. First, they experience sensory deprivation during a crucial phase of neuronal

20 development: Cortical pathways begin to form in utero, and synaptogenesis peaks between

21 the first and fourth year of life. Hearing deprivation during this sensitive period affects the

22 development of the auditory system and higher-order neurocognitive and psychosocial

23 processes (Kral et al., 2016). Second, HL disrupts social-affective processes behind peer 
1 communication and caregiver-guided language learning (Markman et al., 2011). Although

2 caregivers often compensate for a child's HL-for example by speaking more clearly

3 (Houston et al., 2012) — the amount and interactivity of spoken language interactions

4 between caregivers and children decrease with increasing severity of HL (VanDam et al.,

5 2012). Moreover, parental spoken language input to children with a HL is often more

6 directive and less responsive-which is associated with poorer language outcomes

7 (Ambrose, Walker, Unflat-Berry, Oleson, \& Moeller, 2015; Nittrouer, 2010). Additionally, the

8 high prevalence of behavioral problems among children with HL (Barker et al., 2009;

9 Quittner et al., 2010; Topol, Girard, Pierre, Tucker, \& Vohr, 2011) might contribute to

10 parenting stress, which in turn affects mother-infant interactions and children's language

11 skills (Quittner et al., 2010; Vohr et al., 2010).

12 Children's exposure to spoken language (speech and speech in noise) can be

13 quantified with N6 data logs. Busch et al. (2017) showed that, before the age of six, children

14 with CI were exposed to around 4 hrs/day of speech, while 6-18 year-olds heard around 5

15 hours of speech per day. Similar results were reported by others (Cristofari et al., 2017;

16 Easwar et al., 2016; Oberhoffner et al., 2018). Note however, that N6's speech counts include

17 not only the spoken language that is presented to children by their environment, but also

18 their own language production. All studies showed large variability within age groups: In

19 Busch et al. (2017), for example, the difference in average daily exposure to speech between

20 children in the top and bottom quartiles of the distribution was $2 \mathrm{hrs} /$ day. This variation

21 likely reflects sustained differences rather than temporary fluctuations, because N6 data

22 logs normally represent long time periods-namely the period between the CI user's visits

23 to their CI clinic. In the sample used by Busch et al. (2017), data logs covered between two 
1 weeks and over a year, with a median of 48.9 days. Moreover, most participants had

2 contributed multiple data logs.

\section{Exposure to Noisy Environments}

4 Background noise can impede auditory and cognitive performance, and affect language

5 learning (Klatte, Bergström, \& Lachmann, 2013; Kujala \& Brattico, 2009; B. T. M. McMillan

6 \& Saffran, 2016). CI users are particularly vulnerable to noisy listening conditions, because,

7 compared to $\mathrm{NH}$ listeners, the signal that they receive is highly degraded. This affects

8 speech comprehension in noise (Davies, Yellon, \& Purdy, 2001; Moreno-Torres, Madrid-

9 Cánovas, \& Blanco-Montánez, 2016), hampers incidental learning (Vermeulen, De Raeve,

10 Langereis, \& Snik, 2012), and causes more cognitive fatigue (Pichora-Fuller et al., 2016). At

11 the same time, noise is omnipresent in many children's environments (Evans, 2004; Pujol

12 et al., 2012; Shield \& Dockrell, 2008) and children with CIs are no exception: Data log data

13 of Busch et al. (2017) show that the time spent in noisy environments was around 3.4

$14 \mathrm{hrs} /$ day for children under six years of age, and around 5 hrs/day for school-aged children.

15 The variation in exposure to speech was large, too: The $25 \%$ of children who spent the

16 most time in noisy environments were exposed to around $2 \mathrm{hrs} /$ day more noise than the

$1725 \%$ of children who spent the least time in noisy environments. On average, around 2.5-

183.5 hrs of children's daily exposure to noisy environments were accounted for by speech in

19 noise. In fact, about two thirds of the speech that children were exposed to was presented

20 in background noise. Again, similar numbers were reported by other studies (Cristofari et

21 al., 2017; Oberhoffner et al., 2018).

22 Assistive listening devices like remote microphones can alleviate the effects of noise

23 in the classroom (Bertachini et al., 2015; Davies et al., 2001) and facilitate parent-child 
1 communication in difficult acoustical situations (Allen et al., 2017). Yet, Busch et al. (2017)

2 found that before the age of six, only one in five children with a CI was using assistive

3 listening devices, and among those who did, the median duration of use was just around 17

4 min per day. Furthermore, only half of the school-aged children used such devices, and

5 most of those who did, only used them for around 30-40 min per day. Notably, some sounds

6 that N6 classified as noise could be speech with a low signal-to-noise ratio (SNR), such as

7 background conversations and might actually contribute to language learning, because it

8 has been shown that children can pick up new words from overheard speech (Boderé \&

9 Jaspaert, 2017).

\section{Can Data Logs Predict Language Outcomes?}

11 In summary, better spoken language outcomes would be expected for children who use

12 their CI consistently, receive enough spoken language input, and experience little

13 background noise. In all three aspects, N6 data logs show large variation, and it stands to

14 reason that this explains some variance in language outcomes. However, there is still little

15 evidence for associations between children's CI data logs and their language performance.

16 The only published study is one by Guerzoni and Cuda (2017), who logged speech exposure

17 for the first year after implantation. Although all ten participants had received their CI

18 between 10 and 24 months of age, and used it throughout waking hours, there were vast

19 differences in their average daily exposure to speech (0.9-2.6 hrs/day) and speech in noise

$20 \quad(0.8-4.8 \mathrm{hrs} /$ day). Exposure to speech below $70 \mathrm{~dB}$ explained $72 \%$ of the variance in

21 vocabulary skills one year after implantation. However, the environmental differences and

22 their correlation with language outcomes may have been driven by uncontrolled mediating

23 variables_-such as the amount of $\mathrm{CI}$ use. A multivariate analysis is required to further 
1 explore associations between the auditory environment and rehabilitation outcomes of

2 children with CIs, and the explanatory value of N6 data logs.

\section{Aim of the Study}

4 This study investigates associations between children's N6 CI data logs and their language

5 performance, specifically their receptive vocabulary. We conducted a multivariate analysis

6 to determine whether data logs can explain variance beyond that explained by other

7 common predictors of language development—such as chronological age, age at

8 implantation, educational placement, or implantation mode (i.e., unilateral vs. bilateral

9 implantation). Because little is known about potential associations between CI data logs

10 and language performance, we used model selection to explore a wide range of competing

11 hypotheses, and model averaging to account for modeling uncertainty.

12 If differences in data logs are associated with differences in vocabulary, this would

13 provide further evidence for an association between the auditory environment and the

14 language outcomes of children with CI. It would also show that CI data logs can help to

15 identify and address problems in children's environments, making them a useful tool for

16 intervention and naturalistic research. The absence of such associations might indicate that

17 the link between environment and language outcomes is weak or that the current data

18 logging system does not capture these associations and requires further improvements.

\section{MATERIALS AND METHODS}

20 This was a cross-sectional, retrospective analysis, based on a convenience sample of

21 pediatric CI patients. The children's data had been collected as part of the clinical routine at

22 the Radboud UMC Nijmegen (The Netherlands). Prior to the data collection, parents of all 
1 participants had given informed consent for the use and publication of their child's

2 assessment data. The study was approved by the UZ Leuven / KU Leuven Medical Ethical

3 Committee (approval number B322201523779) and was conducted in accordance with the

4 Radboud UMC's ethical standards.

\section{Final Sample}

6 The final sample contained $n=73$ Peabody Picture Vocabulary Test (PPVT) results, data

7 logs for the year preceding each test, and other information about the children from $n=52$

8 children with CIs (21 female, 31 male). The dependent variable was the children's

9 receptive vocabulary. It was measured with the PPVT Standard Score (SS), which has a

10 mean of 100 and a $S D$ of 15 in the age-matched norm population. Details on the data

11 selection and pre-processing are provided below.

\section{Selection of Participants and PPVT Test Results}

13 At the Radboud UMC, there were 211 children who used an N6 CI sound processor. From

14 these, we excluded children who were implanted after the age of three $(n=49)$,

15 postlingually deaf (i.e., after 1.5 years of age; $n=2$ ), not from a predominantly orally

16 communicating Dutch speaking home $(n=16)$, or diagnosed with intellectual disability or

17 severe motor deficits $(n=10)$. For all others, we gathered their Peabody Picture

18 Vocabulary Test (PPVT) results from the clinical records and extracted their sound

19 processor data logs from the clinic's Custom Sound ${ }^{\circledR}$ CI fitting software (Cochlear Ltd.,

20 Sydney, Australia). We included results from all PPVTs taken before 14 years of age, and

21 where CI data logs were available for the year before the test. Nine of the 85 PPVT results

22 that met these criteria were excluded, because less than $70 \%$ of the preceding year were

23 covered by data logs-likely, because the children had only recently received their CI or 
1 upgraded their sound processor. For the remaining PPVT results, the preceding year was

11 hence used their CI for just $0.37 \mathrm{hrs} /$ day. In the other two cases, we were unable to find an

12 explanation for the low CI use (0.90 and $2.27 \mathrm{hrs} /$ day, respectively), but we nevertheless

13 chose to exclude them because a simple 12-month average would likely misrepresent these

14 children's day-to-day auditory input: Our analysis is based on the assumption that children

15 receive a more or less steady auditory input over the course of a year, with a relatively

16 stable mix of the various auditory environments.

\section{Aggregation of CI Data Logs}

18 The final sample contained 456 N6 CI data logs, with a median duration of 96 days $(I Q R=$

19235 , range: $1-779$ days). On average, each child contributed 8.33 data logs $(S D=5.52)$,

20 with a mean length of 203 days $(S D=109)$. Based on these data logs, we calculated

21 children's average daily amount of CI use for the year leading up to each PPVT test moment, 22 and obtained information about their auditory environment-namely their average daily 
1 exposure to speech, speech in noise, noise, all speech (speech in quiet + speech in noise), all

2 noise (speech in noise + noise), music, and quiet.

3 Each N6 CI data log covers the time between two consecutive clinic visits, and

4 contains a counter for each auditory environment that N6 can distinguish. These counters

5 track the time that users spend in these environments, even if the scene classifier is not

6 used to adjust the signal path - that is, if the so-called SCAN feature is not activated.

7 However, when accessories, such as FM or telecoil, are used, all input is counted towards a

8 dedicated accessory counter. Total CI use can be calculated as the sum of the time spent in

9 all auditory environments plus the time using accessories. Whenever the sound processor

10 is connected to the clinic's Custom Sound CI fitting software, the counter values are

11 transferred to a database on the clinic's computer, and the sound processor data log is

12 reset. Because the duration of the data log is known (i.e., the time since the last clinic visit),

13 the counters can be converted into daily averages.

14 To aggregate all data logs from a given 12-month window into a single average, some

15 preprocessing was necessary: If a data log exceeded the 12-month window, we first reduced

16 its counter values for CI use and time spent in each auditory environment proportional to

17 the excess. If the 12-month window was not fully covered by data logs, counters for the gap

18 were estimated from the average of the previous and next log, weighted by their respective

19 durations. If two data logs overlapped (e.g., data logs from bilateral CI users), the higher

20 one of the corresponding counters was used for the overlap, respectively. Eventually, the

21 corrected counters for each 12-month window were summed and divided by 365 to obtain

22 average hrs/day for all data-logging variables. 


\section{Other Variables}

2 For each child, information was retrieved from clinical records about their date of birth,

3 gender, age at implantation, and etiology of deafness. We also determined the children's

4 implantation mode-that is, whether they were currently using one or two CIs (i.e.,

5 bilateral implantation), and what their educational placement was at the time of the data

6 collection. Table 1 shows the sample characteristics.

$7 \quad$ We categorized etiology of deafness as either genetic $(n=25)$, infection $(n=9)$, or

8 unknown $(n=18)$. The children's implantation mode was categorized as unilateral $(n=16)$ if

9 they were using only one CI, bilateral simultaneous $(n=17)$ if there had been less than one-

10 year between implantations, and bilateral sequential $(n=19)$ if there was more than one

11 year between implantations. This grouping is in line with results from Gordon \& Papsin

12 (2009), who found that outcomes of bilateral implantation were best-and similar to those

13 of simultaneous implantation-when the inter-implant delay was one year or less. A child's

14 educational placement was categorized as mainstream $(n=27)$ if the child attended a

15 mainstream school or daycare with at most a so-called light educational arrangement. This

16 means that the child follows a regular curriculum in a mainstream classroom, potentially

17 with some special measures to compensate for the HL and occasional support from a co-

18 teacher, sign language interpreter, or note-taker. All other educational arrangements were

19 categorized as special $(n=25)$, including one child who did not yet attend daycare at 2.8

20 years of age. Since all children in our sample were predominantly orally communicating, all

21 education placements were also predominantly oral. Notably, implantation mode and

22 educational placement could only be determined for the time of the data collection and

23 could have been different for a child's earlier PPVT test moments, for example if the 
1 children had since changed their educational setting or received a second CI. We had

2 initially planned to use audiological test results as a surrogate for factors like pre-implant

3 and residual hearing, or the quality of the electro-neural interface. Unfortunately, these

4 tests had not been conducted uniformly enough to be used in the analysis.

$5 \quad$ For each PPVT test result, we calculated the child's chronological age and hearing

6 age at the test moment, where hearing age refers to the time since the implantation of the

7 first CI. The mean chronological age at the PPVT test moment was $M=7.2$ years $(S D=3.6$,

8 range: 2.1-13.9 years of age). The age distribution was bimodal, with a gap around six years.

9 This was because children who were implanted about 5 years prior to the data collection

10 were still using a sound processor of the previous generation, without the data logging

11 feature.

\section{Model Selection and Averaging}

13 To find the best combinations of data-logging variables and other variables to predict

14 receptive vocabulary (i.e., PPVT SS) we used model selection based on the small-samples

15 corrected Akaike's information criterion (AICc; Burnham \& Anderson, 2002). The AICc

16 combines a likelihood-based measure of model fit with a penalty for model complexity. We

17 used AICc to evaluate a set of candidate models and rank them by their difference in AICc

18 from the best model in the set $(\triangle \mathrm{AICc})$. Models with $\triangle \mathrm{AICc}<2$ are commonly considered to

19 be as well supported by the data as the best model (Symonds \& Moussalli, 2011). Using this

20 threshold, we obtained three subsets of models that best predicted the PPVT SS:

21 (1) Models that did not include data-logging variables, but any combination of

$22 \quad$ other variables

23 (2) Models using a combination of data-logging variables and age 
(3) Models combining data-logging variables and other variables

Additionally, AICc-weights were computed for each model, representing the degree

3 of belief that it is the best model in its set (Wagenmakers \& Farrell, 2004). These weights

4 were used to determine the relative importance of each predictor and compute a weighted

5 average model for each of the three sets. For the calculation of the averages, coefficients

6 that did not occur in a submodel were treated as if it they were zero. These so-called full

7 averages cause shrinkage and thus produce more conservative average coefficients.

8 All continuous predictors were $z$-standardized. Because some children had taken

9 multiple PPVT tests, all models contained random intercepts for participants (most

10 children had taken one $[n=34]$ or two [ $n=16]$ PPVTs. For two children, results were

11 available from three and four tests, respectively). Due to the limited number of repeated

12 measurements, random slopes for age could not be estimated. Notably, PPVT SSs lower

13 than 55 had been recorded as 55 (i.e., left-censored). Because this only concerned three data

14 points, we used these left-censored scores as is. To quantify variance in PPVT SSs explained

15 by each model, we used marginal $\mathrm{R}^{2}$ for mixed models, $R_{m}^{2}$ (Nakagawa \& Schielzeth, 2013).

16 All analyses were carried out in R (version 3.5.0; R Core Team, 2018). The models were fit

17 using lme4 (version 1.1-17; Bates, Mächler, Bolker, \& Walker, 2015) and maximum-likelihood

18 estimation. Model selection was performed with the MuMIn package (version 1.40.4;

19 Bartón, 2017). 


\section{RESULTS}

\section{Descriptive Statistics}

3 For each of the $n=73$ PPVT SSs in our sample (see also Table 1), we aggregated

4 information about the 12 months before the test from the child's CI data logs, namely their

5 average daily exposure to different auditory environments and overall CI use. The variation

6 in the data logs was large: For example, CI use ranged from 3.04-14.18 hrs $/$ day $(I Q R=$

7 4.07), exposure to speech (all speech) from 1.37-7.43 hrs/day $(I Q R=1.95)$, and exposure

8 to noise (all noise) from $0.87-5.86 \mathrm{hrs} /$ day $(I Q R=1.46$; see Table 2 and Supplemental

9 Digital Content, Figure S1, which shows the distributions of the data logging variables).

10 There were strong, positive associations between many data logging variables. Accordingly,

11 a given data logging variable could often be used to predict other data logging variables-

12 with standardized regression coefficients that were frequently far exceeding $\beta=.5$, (e.g.,

13 speech in noise and CI use, $\beta=0.89, \mathrm{p}<.05$; see Supplemental Digital Content, Figure S2,

14 which shows pairwise associations between data logging variables).

15 Descriptively, children in mainstream education used their CI for about $1 \mathrm{hr} /$ day

16 more than children in special education (mainstream: $10.56 \mathrm{hrs} / \mathrm{day}, S D=2.65$, special: 9.54

$17 \mathrm{hrs} /$ day, $S D=2.47$ ), and it was therefore no surprise that they also had slightly higher

18 average daily exposure to almost all auditory scenes-with music being the only exception

19 (mainstream: $M=0.96 \mathrm{hrs} /$ day, $S D=0.52$, special: $M=1.15 \mathrm{hrs} / \mathrm{day}, S D=0.45$; see Table 2

20 and Figure 1). This difference in music exposure was especially pronounced for older

21 children (>6 yrs of age; Figure 1$)$.

The age-related changes in children's average auditory environments were similar to

23 those in Busch et al. (2017)'s much larger sample. There were, for example, an increase in 
1 noise and speech in noise exposure during primary school age, and a decrease of music

2 exposure throughout childhood. Nevertheless, for any auditory scene, children with very

3 low or high exposure could often be found across the entire age range (Figure 1).

4 The PPVT SS—our dependent variable—was approximately normally distributed,

5 with $M=91.4$ and $S D=16.5$ (Figure 2a). Descriptively, there was no discernible effect of

6 chronological age on PPVT SSs (Figure 2b), which is unsurprising because the PPVT SS is

7 normalized by chronological age. However, SSs of children in special education $(M=83.5$,

$8 S D=17.5)$ differed from those of children in mainstream education $(M=98.6, S D=11.6$; see

9 Table 1). While the lowest SS of any child in mainstream education was $81,40 \%$ of children

10 in special education had scores that were lower than that (Figure 2).

11 With regards to the aim of our study, we were most interested in the association

12 between data-logging variables and the PPVT SS. The scatterplots in Figure 3 give some

13 indications of such associations: for example, there appears to be a positive association

14 between average daily CI use and the PPVT SS. Moreover, it seems that the children who

15 have had the least exposure to music tended to have the highest PPVT SSs. However, as

16 mentioned above, to fully understand the connection between the environment and the

17 language outcomes one should consider all data-logging variables and other variables (e.g.,

18 age, educational placement) simultaneously. Moreover, the clustering of observations

19 within subjects must be accounted for. To this end, we used hierarchical linear models,

20 model selection, and model averaging to determine how well PPVT SSs can be predicted

21 from different combinations of data-logging variables, other variables, and both. 


\section{Best Models Without Data-Logging Variables}

2 The first set of models predicted the PPVT SS without using data-logging variables but

3 using any possible combination of the other variables-that is, chronological age,

4 educational placement (special vs. mainstream), gender, age at implantation, implantation

5 mode (unilateral $\mathrm{CI}$ vs. bilateral $\mathrm{CI}$ ), and etiology (genetic, infection, other). Hearing age was not used as a predictor, because it was strongly correlated with chronological age,

$7 \quad \mathrm{r}(70)=.99,(p<.001)$.

The model with the best (lowest) AICc explained $R_{m}^{2}=24 \%$ of the variance in PPVT

9 SSs, using only educational placement as a predictor. The other two models in the best

10 model subset (i.e., with $\Delta \mathrm{AICc}<2$ ) also included chronological age and gender, respectively,

11 but they did not fit substantially better and had lower AICc-weights. Accordingly, the most

12 important predictor in the average model was educational placement. The predicted

13 difference in PPVT SSs between a child in special and mainstream education was $b=16.1$

14 points $(S E=3.9)$, whereas chronological age and gender had comparatively small effect

15 sizes and large standard errors (see Table 3).

\section{Best Models with Only Data-logging Variables}

17 The second set of models predicted the PPVT SS using any combination of chronological

18 age and data-logging variables, namely daily $\mathrm{CI}$ use and average daily exposure to speech,

19 speech in noise, all speech, noise, music, and quiet. We did not include exposure to all noise

20 as a potential predictor, because it was strongly correlated with exposure to speech in

21 noise, $\mathrm{r}(70)=.99, p<.001$ (see also Supplemental Digital Content, Figure S2). We also

22 allowed for interactions of chronological age with any data-logging variables, interactions 
1 of daily CI use with exposure to speech, speech in noise, and all speech, and interactions of exposure to all speech with exposure to speech and speech in noise.

All but one of the seven best models contained chronological age, daily CI use, daily exposure to music and an interaction between music exposure and age. This combination of

5 predictors also had the lowest $\Delta$ AICc and explained $R_{m}^{2}=32 \%$ of the variance in PPVT SSs.

6 In addition to these variables, other models also included daily exposure to speech, speech

7 in noise, all speech, and noise-yet never at the same time. All these models had a similar

8 model fit. Only model 6 fits the data considerably better $\left(R_{m}^{2}=41 \%\right)$, albeit at the cost of

9 parsimony: Compared to the model with the lowest $\triangle \mathrm{AICc}$, this model additionally included

10 daily exposure to speech, as well as interactions of chronological age with daily CI use and

11 daily exposure to speech. The penalty that is associated with this high number of

12 parameters is the reason why model 6 did not outperform other models in terms of AICc.

13 Conversely, model 5 had a comparable AICc value to the best model in the set, but a much

14 poorer fit $\left(R_{m}^{2}=21 \%\right)$, using nothing but daily exposure to quiet as a predictor. Because

15 daily exposure to music and daily CI use were consistently included in the best models, the

16 averaged model coefficients further emphasized their relative importance compared to

17 other data-logging variables (see Table 4).

\section{Best Models Combining Data-logging Variables and Other Variables}

19 The third set of models predicted the PPVT SS using any combination of data-logging

20 variables and other variables that appeared in the previous two best-model sets-namely

21 chronological age, educational placement, gender, daily CI use, and daily exposure to

22 speech, speech in noise, noise, music, all speech, and quiet. We also allowed for interactions

23 of data-logging variables with age and educational placement. 
All of the best models (i.e., with $\Delta \mathrm{AICc}<2$ ) included chronological age, music, daily $\mathrm{CI}$ use, and educational placement-the same four variables that had consistently appeared in

3 the best models with only data-logging variables and only other variables. Notably, all

4 models also contained at least one of the three speech metrics. The model with the lowest

5 (best) AICc included daily exposure to speech in noise, its interaction with educational

6 placement and an interaction of chronological age and daily exposure to music; it explained

$7 \quad R_{m}^{2}=51 \%$ of the variance in PPVT SSs. The other models achieved comparable $R_{m}^{2}$, including

8 daily exposure to all speech or daily exposure to speech as predictors. Because the AICc-

9 weights were similar across all models in the set, the average model emphasized the

10 importance of the four predictors that occurred in all models, whereas the less consistently

11 included speech metrics had small average coefficients with large standard errors (see

12 Table 5). We used the average model to predict mean PPVT SSs as a function of daily CI use

13 and music exposure for both kinds of educational placement and for different exemplary

14 ages, namely at the sample's mean chronological age and approximately $1 S D$ above and

15 below the mean. The predictions are shown in Figure 4.

\section{Decision Boundaries of the Auditory Scene Classifier}

17 When interpreting the data logs, it should be kept in mind, that N6's auditory scene

18 classifier relies on a combination of acoustical features and might activate the same

19 environment in very different environments. For example, to distinguish speech, speech in

20 noise, and noise, the classifier relies — to some extent-on the modulation depth of the

21 signal as an approximation of the signal-to-noise ratio (SNR). This means that an

22 environment classified as noise might contain spoken language at a low SNR (e.g., speaking

23 in a noisy restaurant). Similarly, the music environment might be activated in situations 
1 which merely contain music as background noise, for example, from radio or TV. In order to

2 better understand the auditory scene classifier's behavior, we determined the SNRs at

3 which it switches between the speech, speech in noise, and noise scenes. To that end, we

4 positioned an N6 sound processor in a sound booth and presented it with concatenated

5 LIST sentences (Van Wieringen \& Wouters, 2008) at $70 \mathrm{dBA}$. The speech signal was mixed

6 with four-talker babble noise at decreasing SNRs. We found that the classifier transitioned

7 from the speech environment to the speech in noise environment at around $15 \mathrm{~dB}$ SNR, and

8 from speech in noise to noise at around $-5 \mathrm{~dB}$ SNR.

\section{DISCUSSION}

10 Like previous studies, we found wide interindividual variation in data logs of children with

11 CI (Busch et al., 2017; Cristofari et al., 2017; Easwar et al., 2016; Oberhoffner et al., 2018;

12 Wiseman \& Warner-Czyz, 2018). Moreover, we showed that these differences are

13 correlated with differences in language performance, particularly receptive vocabulary.

\section{Effects of Data-logging Variables}

15 The most strongly associated with vocabulary scores were the average daily amount of CI

16 use and exposure to music. In the models that used data-logging variables and other

17 variables (Table 5), a $1 S D$ increase in daily CI use was, on average, associated with an

18 increase in the PPVT SS of $b=13.2$ points, which is almost $1 S D$ of the PPVT SS in the norm

19 population. This finding is in line with the literature, which stresses the importance of

20 consistent hearing device use for auditory rehabilitation (Walker, Holte, et al., 2015; Wie et

21 al., 2007). For example, Easwar et al. (2018) have found that longer daily CI use is

22 associated with better speech perception abilities in children with a CI. Specifically, a one 
1 hour increase in daily CI use was associated with a $2.6 \%$ increase in speech perception test

2 scores when factors like age and length of CI experience were controlled for.

3 The strong negative effect of music exposure, on the other hand, came as a surprise.

4 A $1 S D$ increase in daily music exposure was associated with a decrease in PPVT SSs of $b=$

$5 \quad-5.7$ points. One possible explanation for this is that background music effectively acts as

6 noise which hinders language learning. It is also possible that some part of what was

7 classified as music was actually TV, because N6 tends to classify children's TV programs as

8 music (Hanvey \& DeBold, 2015). Higher amounts of TV in children's homes have been

9 associated with decreased quality of parent-child communication and decreased child

10 language performance (Ambrose et al., 2014; Christakis et al., 2009).

11 The connection between the speech exposure metrics and PPVT SSs was less clear:

12 In the best models, daily exposure to speech, speech in noise, and all speech appeared as

13 predictors, but in various combinations (Table 5). This uncertainty was reflected in the

14 small average coefficients. Thus, while the three speech scenes do seem to contribute to

15 predicting PPVT SSs, their contribution is small, and they appear to be somewhat

16 interchangeable. In part this might be due to the strong correlations between them (see

17 Supplemental Digital Content, Figure S2). While there is no doubt that meaningful language

18 input is crucial for language development (e.g., Hoff, 2006), it is possible that the N6

19 classifier's speech classes are not well aligned with those aspects of the language

20 environment that drive language development. For example, N6 does not distinguish

21 between language input and output, thus mixing environmental influences and their effects.

22 Furthermore, sheer quantity of language input may not be as predictive as, for example,

23 interactivity of parent-child communication (Ambrose et al., 2014; VanDam et al., 2012). 
1 Separating own and external speech and adding information about the quality of spoken

2 language interactions (e.g., their interactivity) could bring more clarity into these issues

3 and improve the predictive power of data logs.

Additional uncertainty is introduced to the speech metrics because of varying

5 accessory use. When accessories such as FM, telecoil, or wireless audio streaming are being

6 used, the classifier is inactive, and all input is instead counted towards a dedicated

7 accessory scene. Thus, it remains unclear how much speech the children have heard

8 through accessories. However, the children in our sample barely used accessories: The

9 median accessory use was just $0.01 \mathrm{hrs} /$ day (Table 2). Similar to the results of Busch et al.

10 (2017), accessory use differed between preschool and school-aged children. Of 30 data

11 points taken before the age of six, only one indicated more than $5 \mathrm{~min} /$ day of accessory use,

12 whereas 29 out of 43 data points from the 6-14 year old children did (median $=0.62$

$13 \mathrm{hrs} /$ day, IQR $=1.05$, range: $0-2.76)$. On the one hand, this means that the auditory scene

14 classifier has categorized almost all auditory input that the children have received, and that

15 the data logs provide a relatively complete picture of their auditory environments. On the

16 other hand, the low accessory use is concerning, because accessories can support CI users

17 in adverse listening conditions: in noisy classrooms, FM or similar remote microphone

18 systems can help by directly streaming the teacher's voice to the child's hearing device

19 (Bertachini et al., 2015; Davies et al., 2001; Iglehart, 2004; Razza, Zaccone, Meli, \& Cristofari,

20 2017), and even at home, they can promote parent-child interactions by allowing spoken

21 language communication in situations in which it would otherwise be difficult-for

22 example in the car (Allen et al., 2017). 
We also found no clear evidence of an association between daily exposure to noisy environments and the PPVT SS. Noise decreases speech understanding of CI users (Davies

3 et al., 2001), increases listening effort (Pichora-Fuller et al., 2016), and interferes with

4 language learning (Klatte et al., 2013; Kujala \& Brattico, 2009; B. T. M. McMillan \& Saffran,

5 2016; Vermeulen et al., 2012). Hence, chronic exposure to noise would be expected to

6 interfere with cognitive and language development (Klatte et al., 2013; Kujala \& Brattico,

7 2009). Perhaps, the association between daily noise exposure and language performance is

8 too ambiguous: a noisy environment can be an obstacle for language learning or a sign of

9 robust language skills and good integration in the mainstream. Moreover, the effects of

10 background noise might be ameliorated by the sound processor's noise reduction (NR)

11 features. Plasmans et al. (2016) have found that with NR, pediatric CI users were able to

12 understand around 9.4\% more words and 16.7\% more sentences in noise. Mauger et al.

13 (2014) have shown that NR helped adult N6 users to achieve 50\% sentence understanding

14 at SNRs as low as $-7.6 \mathrm{~dB}$ (as opposed to $-2.8 \mathrm{~dB}$ when NR was deactivated). Yet, the

15 classifier already transitions from the speech environment to the speech in noise

16 environment at around $15 \mathrm{~dB}$, and from speech in noise to noise at around -5 dB SNR (see

17 methods section). Thus, it is possible that a lot of what is classified as speech in noise by N6

18 can be understood well, due to NR (cf. Razza et al., 2017, who found no significant benefit of

19 N6's NR on children's speech in noise performance). The association between exposure to

20 noisy environments and language performance might be further weakened because some

21 children have NR activated while others do not.

22 Although we found no clear association between the speech and noise metrics and

23 receptive vocabulary, this does not preclude the existence of such associations for other 
1 language domains. While word learning certainly depends on language input (e.g., Hoff \&

2 Naigles 2002) and can be hampered by background noise (B. T. M. McMillan \& Saffran,

3 2016), it is conceivable that vocabulary is more robust against environmental influences

4 than other domains of language. Morphosyntax, for example, relies on subtle acoustical

5 cues which are difficult to pick up with a CI to begin with (Markman et al., 2011), and might

6 therefore benefit more from repetition and noise-free presentation. Similarly, more subtle

7 language deficits might be revealed by more complex tasks like narrative production

8 (Boons et al., 2013; Rinaldi, Baruffaldi, Burdo, \& Caselli, 2013). Thus, associations between

9 other language domains and data logs should be investigated.

\section{Effects of Other Variables}

11 We found that children in mainstream education had higher PPVT SSs than those in special

12 education. Similar group differences have been reported by others (Boons et al., 2013;

13 Geers, Nicholas, \& Moog, 2007). It is possible that this reflects a beneficial effect of

14 mainstream education on language development, or that it merely indicates that children

15 with age appropriate language levels are more likely to be placed in mainstream education.

16 Age was not an important predictor in the models without data-logging variables.

17 This is no surprise, since PPVT SSs are normalized for age. A missing age effect also

18 indicates that there was no evidence that the CI users, as a group, were developing at a

19 significantly different pace than their $\mathrm{NH}$ peers in the test's normative sample. However, age

20 became an important factor when data-logging variables were included in the models, often

21 in an interaction with one of them (Tables 4 and 5). That is, age mostly helped to improve

22 predictions when combined with data-logging variables, but not by itself. Such interactions

23 might indicate that the effect of the data-logging variables on language performance 
1 changes with age. This is not surprising, given the age-related changes in the children's

2 auditory environments that we found. For example, while it was normal for a 3-year old to

3 have an average of around 4 hrs of exposure to speech per day, this would be rather low for

4 a child above six years of age (Figure 1).

5 Besides educational placement and age, none of the other variables (i.e., gender, age

6 at implantation, implantation mode, and etiology) had a clear effect on PPVT SSs, even

7 though all of them were previously found to be important-for example, gender (Le

8 Normand \& Moreno-Torres, 2014), implantation mode (Boons et al., 2012; Sparreboom et al.,

9 2015), age at implantation (Holt \& Svirsky, 2008; Svirsky, Teoh, \& Neuburger, 2004), and

10 hearing age (Walker, Holte, et al., 2015). This discrepancy could be due to measurement

11 error or due to the homogeneity of our sample with respect to these factors.

\section{Complementarity of Data-logging Variables and Other Variables}

13 It is conceivable that data-logging variables and other variables merely capture the same

14 information in different form. For example, special schools in which sign language is used

15 likely also provide less spoken language exposure. Here we found that data-logging

16 variables explained more variance in PPVT SSs than other variables, and when both were

17 combined, predictions improved further. This supports the notion that the data-logging

18 variables captured information that was not contained in the other variables-at least not

19 in the ones we have assessed. There is, however, a range of factors that we did not

20 assess-or only coarsely. No information was available for some well-established

21 predictors of language performance, like SES, pre-implant hearing experience, or residual

22 hearing (Geers et al., 2007; Niparko et al., 2010). To some degree, these factors might have

23 been reflected in the data logs: Low SES, for example, is associated with poorer language 
1 environments (Hart \& Risley, 1995; Hoff, 2015; Huttenlocher, Waterfall, Vasilyeva, Vevea, \&

2 Hedges, 2010; Rowe, 2008; Vohr et al., 2010), more noisy environments (Evans, 2004;

3 Pujol et al., 2012), and less hearing device use (Marnane \& Ching, 2015; Walker, McCreery,

4 et al., 2015; Walker et al., 2013). Similarly, complex family issues (e.g., death or divorce) are

5 associated with decreased daily CI use (Archbold et al., 2009; Marnane \& Ching, 2015).

6 Thus, if we had been able to add these factors into the analysis, they might have explained

7 additional variance and altered the estimates of the links between data logs and

8 vocabulary.

\section{Limitations}

10 We explored a wide range of models for the association between data logs and language

11 performance. While some argue that this approach to model selection is appropriate when

12 exploration is the primary goal (Symonds \& Moussalli, 2011), Burnham and Anderson

13 (2002) warn that fitting too many candidate models can lead to spurious findings. In any

14 case, the associations we found should be interpreted carefully and must be targeted more

15 directly and rigorously in the future. Most importantly, the causal relation between

16 environment and language performance remains unclear: It is possible that certain

17 environments facilitate language development, or that children are placed in environments

18 according to their skills, either because of self-selection or due to decisions made by their

19 caregivers. After all, whether young children go to mainstream education, for example, is

20 usually decided by their parents, teachers, and other caregivers based on their behavior

21 and abilities.

22 Another limitation is our relatively homogenous sample. All children were

23 prelingually deaf, early implanted, mainly communicating orally, and had no known severe 
1 cognitive or motor deficits. All these factors might affect the association between

2 environment and language outcomes. This means, that it is not clear, whether the

3 associations we found hold true for the broader pediatric CI population. In the future, it

4 should be explored how the environment interacts with such child characteristics in

5 shaping the language outcomes.

Another concern is that there is little information about the validity of N6's auditory

7 scene classifier (Hanvey \& DeBold, 2015; Mauger et al., 2014). The classifier has been trained

8 on a large sample of labeled examples, so that it should generally agree with the

9 categorization made by humans, and the 12-month windows we used should have made the

10 averages robust against short-term and seasonal fluctuations. However, empirical evidence

11 for the classifier's validity and reliability in real-world applications is needed.

\section{Conclusion}

13 We have shown, that $\mathrm{CI}$ data logs can be used to make comprehensive, naturalistic

14 observations of children's daily CI use and aspects of their auditory environments, and that

15 the information that data logs capture is associated with children's language performance.

16 Specifically, children's receptive vocabulary scores were predicted by their average daily CI

17 use and exposure to music. Higher amounts of daily CI use were associated with larger

18 vocabularies, and children who were exposed to more music - as labeled by the N6

19 auditory scene classifier - had smaller vocabularies. Somewhat surprisingly, there were no

20 clear associations between the data-logged daily exposure to speech and noise and

21 children's language performance.

22 These findings are encouraging, because a child's daily CI use and environment

23 can —at least in part—be changed through intervention, and data logs can be used to guide 
1 caregivers in making such changes. In fact, there already are intervention programs that use

2 LENA in such a way, in order to help parents increase the quality of their child's language

3 environment (Leffel \& Suskind, 2013; Suskind et al., 2016). While LENA provides more

4 detailed and accurate measurements of the child's auditory environment, CI data logs have

5 the advantage that they are available for all N6 users, and that they can easily be collected

6 over long time periods. Even outside of specific interventions, CI data logs can enrich the

7 communication between clinicians and CI users (or their caregivers), and encourage the

8 latter to take a more active role in the rehabilitation process (Chiauzzi, Rodarte, \&

9 DasMahapatra, 2015; McCurdy, 2016).

10 In summary, our results suggest that consistent daily $\mathrm{CI}$ use and a rich auditory

11 environment play an important role in the language development of children with CIs, and

12 that CI data logs are a valuable clinical tool, that can help to understand this role and

13 support the auditory rehabilitation of children with CIs.

15 This study was supported by the FP7 people programme (Marie Curie Actions), REA grant 16 agreement FP7-607139 (iCARE). 


\section{REFERENCES}

2 Allen, S., Mulla, I., Ng, Z. Y., \& Archbold, S. (2017). Using radio aids with pre-school deaf children (white paper). https://doi.org/10.13140/RG.2.2.10415.02724

4 Ambrose, S. E., VanDam, M., \& Moeller, M. P. (2014). Linguistic Input, Electronic Media, and

5 Communication Outcomes of Toddlers With Hearing Loss. Ear Hear, 35(2), 139-147. https://doi.org/10.1097/AUD.0b013e3182a76768

Ambrose, S. E., Walker, E. A., Unflat-Berry, L. M., Oleson, J. J., \& Moeller, M. P. (2015). Quantity and quality of caregivers' linguistic input to 18-month and 3-year-old children who are hard of hearing. Ear Hear, 36, 48S-59S.

11 Archbold, S. M., Athalye, S., Mulla, I., Harrigan, S., Wolters-Leermakers, N., Isarin, J., \&

12 Knoors, H. (2015). Cochlear implantation in children with complex needs: the

13 perceptions of professionals at cochlear implant centres. Cochlear Implants

14 International, 16(6), 303-311. https://doi.org/10.1179/1754762815Y.0000000012

15 Archbold, S. M., Nikolopoulos, T. P., \& Lloyd-Richmond, H. (2009). Long-term use of cochlear

16 implant systems in paediatric recipients and factors contributing to non-use. Cochlear

17 Implants Int, 10(1), 25-40. https://doi.org/10.1179/cim.2009.10.1.25

18 Barker, D. H., Quittner, A. L., Fink, N. E., Eisenberg, L. S., Tobey, E. A., \& Niparko, J. K. (2009).

19 Predicting behavior problems in deaf and hearing children: The influences of language, 20 attention, and parent-child communication. Dev Psychopathol, 21(02), 373.

$21 \quad$ https://doi.org/10.1017/S0954579409000212 
1 Bartón, K. (2017). Multi-Model Inference (R-package). Retrieved from https://cran.rproject.org/package=MuMIn

Bates, D., Mächler, M., Bolker, B., \& Walker, S. (2015). Fitting linear mixed-effects models using lme4. J Stat Softw, 67(1), 1-48. https://doi.org/10.18637/jss.v067.i01

Bertachini, A. L. L., Pupo, A. C., Morettin, M., Martinez, M. A. N., Bevilacqua, M. C., Moret, A. L. M., ... Jacob, R. T. de S. (2015). Frequency Modulation System and speech perception in the classroom: a systematic literature review. CoDAS, 27(3), 292-300. https://doi.org/10.1590/2317-1782/20152014103

Boderé, A., \& Jaspaert, K. (2017). Six-year-olds' learning of novel words through addressed and overheard speech. J Child Lang, 44(5), 1163-1191. https://doi.org/10.1017/S0305000916000465

Boons, T., Brokx, J. P. L., Dhooge, I., Frijns, J. H. M., Peeraer, L., Vermeulen, A., ... van Wieringen, A. (2012). Predictors of Spoken Language Development Following Pediatric Cochlear Implantation. Ear Hear, 33(5), 617-639. https://doi.org/10.1097/AUD.0b013e3182503e47

Boons, T., De Raeve, L., Langereis, M., Peeraer, L., Wouters, J., \& van Wieringen, A. (2013). Expressive vocabulary, morphology, syntax and narrative skills in profoundly deaf children after early cochlear implantation. Res Dev Disabil, 34(6), 2008-2022. https://doi.org/10.1016/j.ridd.2013.03.003

Burnham, K. P., \& Anderson, D. R. (2002). Model selection and multimodel inference: a practical information-theoretic approach (2nd Editio). New York: Springer.

Busch, T., Vanpoucke, F., \& van Wieringen, A. (2017). Auditory Environment Across the Life 
Span of Cochlear Implant Users: Insights From Data Logging. J Speech Lang Hear Res, 60(5), 1362-1377. https://doi.org/10.1044/2016_JSLHR-H-16-0162

Chiauzzi, E., Rodarte, C., \& DasMahapatra, P. (2015). Patient-centered activity monitoring in the self-management of chronic health conditions. BMC Med, 13(1), 1-6. https://doi.org/10.1186/s12916-015-0319-2

Christakis, D. A., Gilkerson, J., Richards, J. A., Zimmerman, F. J., Garrison, M. M., Xu, D., ... Yapanel, U. (2009). Audible Television and Decreased Adult Words, Infant Vocalizations, and Conversational Turns. Arch Pediatr Adolesc Med, 163(6), 554-558. https://doi.org/10.1001/archpediatrics.2009.61

Cochlear Ltd. (2017). Cochlear internal market share data, Cochlear Services dataset.

Connor, C. M., \& Zwolan, T. A. (2004). Examining Multiple Sources of Influence on the Reading Comprehension Skills of Children Who Use Cochlear Implants. J Speech Lang Hear Res, 47(3), 509-226. https://doi.org/10.1044/1092-4388(2004/040)

Cristofari, E., Cuda, D., Martini, A., Forli, F., Zanetti, D., Di Lisi, D., ... Malerba, P. (2017). A Multicenter Clinical Evaluation of Data Logging in Cochlear Implant Recipients Using Automated Scene Classification Technologies. Audiol Neurotol, 22(4-5), 226-235. https://doi.org/10.1159/000484078

Cruz, I., Quittner, A. L., Marker, C., DesJardin, J. L., \& the CDaCI Investigative Team. (2013). Identification of Effective Strategies to Promote Language in Deaf Children With Cochlear Implants. Child Dev, 84(2), 543-559. https://doi.org/10.1111/j.14678624.2012.01863.x

Davies, M. G., Yellon, L., \& Purdy, S. C. (2001). Speech-in-Noise Perception of Children using 
Cochlear Implants and FM Systems. Australian and New Zealand Journal of Audiology, 23(1), 52-62. https://doi.org/10.1375/audi.23.1.52.31096

DesJardin, J. L., \& Eisenberg, L. S. (2007). Maternal contributions: Supporting language development in young children with cochlear implants. Ear Hear, 28(4), 456-469. https://doi.org/10.1097/AUD.0b013e31806dc1ab

Easwar, V., Sanfilippo, J., Papsin, B., \& Gordon, K. (2016). Factors Affecting Daily Cochlear Implant Use in Children: Datalogging Evidence. J Am Acad Audiol, 27(10), 824-838. https://doi.org/10.3766/jaaa.15138

Easwar, V., Sanfilippo, J., Papsin, B., \& Gordon, K. (2018). Impact of Consistency in Daily Device Use on Speech Perception Abilities in Children with Cochlear Implants: Datalogging Evidence. Journal of the American Academy of Audiology, 29(9), 835-846. https://doi.org/10.3766/jaaa.17051

Evans, G. W. (2004). The Environment of Childhood Poverty. Am Psychol, 59(2), 77-92. https://doi.org/10.1037/0003-066X.59.2.77

Geers, A. E., Nicholas, J. G., \& Moog, J. S. (2007). Estimating the Influence of Cochlear Implantation on Language Development in Children. Audiol Med, 5(4), 262-273. https://doi.org/10.1080/16513860701659404

Geers, A. E., Strube, M. J., Tobey, E. A., Pisoni, D. B., \& Moog, J. S. (2011). Epilogue: Factors Contributing to Long-Term Outcomes of Cochlear Implantation in Early Childhood. Ear Hear, 32(Supplement), 84S-92S. https://doi.org/10.1097/AUD.0b013e3181ffd5b5

Gilkerson, J., Richards, J. A., Warren, S. F., Montgomery, J. K., Greenwood, C. R., Oller, D. K., ... Paul, T. D. (2017). Mapping the early language environment using all-day recordings 

and automated analysis. American Journal of Speech-Language Pathology, 26(2), 248265. https://doi.org/10.1044/2016_AJSLP-15-0169

Gilkerson, J., Richards, J. A., Warren, S. F., Oller, K., Russo, R., \& Vohr, B. (2018). Language Experience in the Second Year of Life and Language Outcomes in Late Childhood. Pediatric, 142(4). https://doi.org/10.1542/ peds.2017-4276

Gordon, K. A., \& Papsin, B. C. (2009). Benefits of short interimplant delays in children receiving bilateral cochlear implants. Otology and Neurotology, 30(3), 319-331.

Guerzoni, L., \& Cuda, D. (2017). Speech processor data logging helps in predicting early linguistic outcomes in implanted children. Int J Pediatr Otorhinolaryngol, 101, 81-86. https://doi.org/10.1016/j.ijporl.2017.07.026

Hanvey, K., \& DeBold, L. (2015). Preschool television programmes: Analysis using SmartSound IQ data logging. Cochlear Implants Int, 16(Suppl 1), S26-S29. https://doi.org/10.1179/1467010014Z.000000000229

Hart, B., \& Risley, T. R. (1995). Meaningful Differences in the Everyday Experience of Young American Children. P.H. Brookes.

Hoff, E. (2006). How social contexts support and shape language development. Dev Rev, 26(1), 55-88. https://doi.org/10.1016/j.dr.2005.11.002

Hoff, E. (2015). The specificity of environmental influence: socioeconomic status affects early vocabulary development via maternal speech. Child Development, 74(5), 13681378. https://doi.org/10.1111/1467-8624.00612

Hoff, E., \& Naigles, L. (2002). How Children Use Input to Acquire a Lexicon. Child Dev, 73(2), 418-433. https://doi.org/10.1111/1467-8624.00415 
1 Holt, R. F., Beer, J., Kronenberger, W. G., \& Pisoni, D. B. (2013). Developmental Effects of Family Environment on Outcomes in Pediatric Cochlear Implant Recipients. Otol \& Neurotol, 34(3), 388-395. https://doi.org/10.1097/MAO.0b013e318277a0af

Holt, R. F., \& Svirsky, M. A. (2008). An exploratory look at pediatric cochlear implantation: Is earliest always best? Ear Hear, 29(4), 492-511. https://doi.org/10.1097/AUD.0b013e31816c409f

Houston, D. M., Beer, J., Bergeson, T. R., Chin, S. B., Pisoni, D. B., \& Miyamoto, R. T. (2012). The Ear is Connected to the Brain: Some New Directions in the Study of Children with Cochlear Implants at Indiana University. J Am Acad Audiol, 23(6), 446-463. https://doi.org/10.3766/jaaa.23.6.7.The

Hurtado, N., Marchman, V. A., \& Fernald, A. (2008). Does input influence uptake? Links between maternal talk, processing speed and vocabulary size in Spanish-learning children. Dev Sci, 11(6), 31-39. https://doi.org/10.1111/j.1467-7687.2008.00768.x

Huttenlocher, J., Waterfall, H., Vasilyeva, M., Vevea, J., \& Hedges, L. V. (2010). Sources of variability in children's language growth. Cogn Psychol, 61(4), 343-365. https://doi.org/10.1016/j.cogpsych.2010.08.002

Iglehart, F. (2004). Speech Perception by Students With Cochlear Implants Using SoundField Systems in Classrooms. American Journal of Audiology, 13(1), 62. https://doi.org/10.1044/1059-0889(2004/009)

Klatte, M., Bergström, K., \& Lachmann, T. (2013). Does noise affect learning? A short review on noise effects on cognitive performance in children. Front Psychol, 4(August), 1-6. https://doi.org/10.3389/fpsyg.2013.00578 
1 Kral, A., Kronenberger, W. G., Pisoni, D. B., \& O’Donoghue, G. M. (2016). Neurocognitive factors in sensory restoration of early deafness: A connectome model. Lancet Neurol, 15(6), 610-621. https://doi.org/10.1016/S1474-4422(16)00034-X

Kujala, T., \& Brattico, E. (2009). Detrimental noise effects on brain's speech functions. Biol Psychol, 81(3), 135-143. https://doi.org/10.1016/j.biopsycho.2009.03.010

Le Normand, M. T., \& Moreno-Torres, I. (2014). The role of linguistic and environmental factors on grammatical development in French children with cochlear implants. Lingua, 139, 26-38. https://doi.org/10.1016/j.lingua.2013.02.012

Leffel, K., \& Suskind, D. (2013). Parent-directed approaches to enrich the early language environments of children living in poverty. Seminars in Speech and Language, 34(4), 267-277. https://doi.org/10.1055/s-0033-1353443

Macaulay, C. E., \& Ford, R. M. (2013). Family influences on the cognitive development of profoundly deaf children: Exploring the effects of socioeconomic status and siblings. J Deaf Stud Deaf Educ, 18(4), 545-562. https://doi.org/10.1093/deafed/ent019

Markman, T. M., Quittner, A. L., Eisenberg, L. S., Tobey, E. A., Thal, D., Niparko, J. K., ... Team, Cd. I. (2011). Language development after cochlear implantation: An epigenetic model. J Neurodev Disord, 3(4), 388-404. https://doi.org/10.1007/s11689-011-9098-z

Marnane, V., \& Ching, T. Y. C. (2015). Hearing aid and cochlear implant use in children with hearing loss at three years of age: Predictors of use and predictors of changes in use. Int J Audiol, 54(8), 544-551. https://doi.org/10.3109/14992027.2015.1017660

Mauger, S. J., Warren, C. D., Knight, M. R., Goorevich, M., \& Nel, E. (2014). Clinical evaluation of the Nucleus $₫ 6$ cochlear implant system: Performance improvements with 
SmartSound iQ. Int J Audiol, 53(8), 564-576. https://doi.org/10.3109/14992027.2014.895431

McCurdy, K. (2016). Visual storytelling in healthcare: Why we should help patients visualize their health. Information Visualization, 15(2), 173-178. https://doi.org/10.1177/1473871615592255

McMillan, A., Durai, M., \& Searchfield, G. D. (2017). A survey and clinical evaluation of hearing aid data-logging: a valued but underutilized hearing aid fitting tool. Speech Lang Hear, 5728(November), 1-10. https://doi.org/10.1080/2050571X.2017.1339942

McMillan, B. T. M., \& Saffran, J. R. (2016). Learning in Complex Environments: The Effects of Background Speech on Early Word Learning. Child Dev, 87(6), 1841-1855. https://doi.org/10.1111/cdev.12559

Moog, J. S., \& Geers, A. E. (2010). Early educational placement and later language outcomes for children with cochlear implants. Otol Neurotol, 31(8), 1315-1319. https://doi.org/10.1097/MAO.0b013e3181eb3226

Moreno-Torres, I., Madrid-Cánovas, S., \& Blanco-Montánez, G. (2016). Sensitive periods and language in cochlear implant users. J Child Lang, 43(3), 479-504. https://doi.org/10.1017/S0305000915000823

Mueller, H. G. (2007). Data logging: It's popular, but how can this feature be used to help patients? Hearing Journal, 60(10). https://doi.org/10.1097/01.HJ.0000295442.16133.d7

Muñoz, K., Olson, W. A., Twohig, M. P., Preston, E., Blaiser, K., \& White, K. R. (2015). Pediatric hearing aid use: Parent reported challenges. Ear Hear, 36(2), 279-287. https://doi.org/10.1097/AUD.0000000000000111 
1 Muñoz, K., Preston, E., \& Hicken, S. (2014). Pediatric Hearing Aid Use: How Can Audiologists Support Parents to Increase Consistency? J Am Acad Audiol, 25(4), 380-387. https://doi.org/10.3766/jaaa.25.4.9

Nakagawa, S., \& Schielzeth, H. (2013). A general and simple method for obtaining R2 from generalized linear mixed-effects models. Methods Ecol Evol, 4(2), 133-142. https://doi.org/10.1111/j.2041-210x.2012.00261.x

Niparko, J. K., Tobey, E. A., Thal, D. J., Eisenberg, L. S., Wang, N.-Y., Quittner, A. L., ... Team, Cd. I. (2010). Spoken language development in children following cochlear implantation. JAMA, 303(15), 1498-1506. https://doi.org/10.1001/jama.2010.451

Nittrouer, S. (2010). Early Development of Children With Hearing Loss. San Diego, CA: Plural Publishing.

Oberhoffner, T., Hoppe, U., Hey, M., Hecker, D., Bagus, H., Voigt, P., ... Hocke, T. (2018). Multizentrische Analyse des Nutzerverhaltens von Cochlea-Implantat-Trägern. Laryngo-Rhino-Otol, 97(5), 313-320. https://doi.org/10.1055/a-0574-2569

Pichora-Fuller, M. K., Kramer, S. E., Eckert, M. A., Edwards, B., Hornsby, B. W. Y., Humes, L. E., ... Wingfield, A. (2016). Hearing Impairment and Cognitive Energy. Ear Hear, 37(Suppl 1), 5S-27S. https://doi.org/10.1097/AUD.0000000000000312

Plasmans, A., Rushbrooke, E., Moran, M., Spence, C., Theuwis, L., Zarowski, A., ... Mauger, S. J. (2016). A multicentre clinical evaluation of paediatric cochlear implant users upgrading to the Nucleus® 6 system. International Journal of Pediatric Otorhinolaryngology, 83, 193-199. https://doi.org/10.1016/j.ijporl.2016.02.004

Pujol, S., Berthillier, M., Defrance, J., Lardiès, J., Petit, R., Houot, H., ... Mauny, F. (2012). Urban 
ambient outdoor and indoor noise exposure at home: A population-based study on schoolchildren. Appl Acoust, 73(8), 741-750. https://doi.org/10.1016/j.apacoust.2012.02.007

Quittner, A. L., Barker, D. H., Cruz, I., Snell, C., Grimley, M. E., Botteri, M., \& CDaCI Investigative Team. (2010). Parenting Stress Among Parents of Deaf and Hearing Children: Associations with Language Delays and Behavior Problems. Parenting, 10(2), 136-155. https://doi.org/10.1080/15295190903212851

Quittner, A. L., Cruz, I., Barker, D. H., Tobey, E., Eisenberg, L. S., Niparko, J. K., \& CDaCI Investigative Team. (2013). Effects of Maternal Sensitivity and Cognitive and Linguistic Stimulation on Cochlear Implant Users' Language Development over Four Years. J Pediatr, 162(2), 343-348.e3. https://doi.org/10.1016/j.jpeds.2012.08.003

R Core Team. (2018). R: A Language and Environment for Statistical Computing. Retrieved from https://www.r-project.org/

Razza, S., Zaccone, M., Meli, A., \& Cristofari, E. (2017). Evaluation of speech reception threshold in noise in young Cochlear ${ }^{\mathrm{TM}}$ Nucleus ${ }^{\circledR}$ system 6 implant recipients using two different digital remote microphone technologies and a speech enhancement sound processing algorithm. International Journal of Pediatric Otorhinolaryngology, 103(July), 71-75. https://doi.org/10.1016/j.ijporl.2017.10.002

Rinaldi, P., Baruffaldi, F., Burdo, S., \& Caselli, M. C. (2013). Linguistic and pragmatic skills in toddlers with cochlear implant. International Journal of Language and Communication Disorders, 48(6), 715-725. https://doi.org/10.1111/1460-6984.12046

Rowe, M. L. (2008). Child-directed speech: relation to socioeconomic status, knowledge of 
child development and child vocabulary skill. J Child Lang, 35(01), 185-205. https://doi.org/10.1017/S0305000907008343

Shield, B. M., \& Dockrell, J. E. (2008). The effects of environmental and classroom noise on the academic attainments of primary school children. J Acoust Soc Am, 123(1), 133-144. https://doi.org/10.1121/1.2812596

Sparreboom, M., Langereis, M. C., Snik, A. F. M., \& Mylanus, E. A. M. (2015). Long-term outcomes on spatial hearing, speech recognition and receptive vocabulary after sequential bilateral cochlear implantation in children. Res Dev Disabil, 36, 328-337. https://doi.org/10.1016/j.ridd.2014.10.030

Suskind, D. L., Leffel, K. R., Graf, E., Hernandez, M. W., Gunderson, E. A., Sapolich, S. G., ... Levine, S. C. (2016). A parent-directed language intervention for children of low socioeconomic status: a randomized controlled pilot study. J Child Lang, 43(02), 366406. https://doi.org/10.1017/S0305000915000033

Svirsky, M. A., Teoh, S.-W., \& Neuburger, H. (2004). Development of Language and Speech Perception in Congenitally, Profoundly Deaf Children as a Function of Age at Cochlear Implantation. Audiol Neurotol, 9(4), 224-233. https://doi.org/10.1159/000078392

Symonds, M. R. E., \& Moussalli, A. (2011). A brief guide to model selection, multimodel inference and model averaging in behavioural ecology using Akaike's information criterion. Behav Ecol Sociobiol, 65(1), 13-21. https://doi.org/10.1007/s00265-010-1037-6

Tamis-LeMonda, C. S., Kuchirko, Y., \& Song, L. (2014). Why Is Infant Language Learning Facilitated by Parental Responsiveness? Curr Dir Psychol Sci, 23(2), 121-126. https://doi.org/10.1177/0963721414522813 
1 Tomblin, J. B., Harrison, M., Ambrose, S. E., Walker, E. A., Oleson, J. J., \& Moeller, M. P. (2015).

Language Outcomes in Young Children with Mild to Severe Hearing Loss. Ear Hear, 36(0 1), 76S-91S. https://doi.org/10.1097/AUD.0000000000000219

Topol, D., Girard, N., Pierre, L. S., Tucker, R., \& Vohr, B. (2011). The effects of maternal stress and child language ability on behavioral outcomes of children with congenital hearing loss at 18-24months. Early Hum Dev, 87(12), 807-811. https://doi.org/10.1016/j.earlhumdev.2011.06.006

van Wieringen, A., \& Wouters, J. (2015). What can we expect of normally-developing children implanted at a young age with respect to their auditory, linguistic and cognitive skills? Hear Res, 322, 171-179. https://doi.org/10.1016/j.heares.2014.09.002

Van Wieringen, A., \& Wouters, J. (2008). LIST and LINT: Sentences and numbers for quantifying speech understanding in severely impaired listeners for Flanders and the Netherlands. Int J Audiol, 47(6), 348-355. https://doi.org/10.1080/14992020801895144

VanDam, M., Ambrose, S. E., \& Moeller, M. P. (2012). Quantity of parental language in the home environments of hard-of-hearing 2-year-olds. J Deaf Stud Deaf Educ, 17(4), 402420. https://doi.org/10.1093/deafed/ens025

Vermeulen, A., De Raeve, L., Langereis, M., \& Snik, A. (2012). Changing Realities in the Classroom for Hearing-Impaired Children with Cochlear Implant. Deaf Educ Int, 14(1), 36-47. https://doi.org/10.1179/1557069X12Y.0000000004

Vohr, B., Pierre, L. S., Topol, D., Jodoin-Krauzyk, J., Bloome, J., \& Tucker, R. (2010). Association of maternal communicative behavior with child vocabulary at 18-24months for children with congenital hearing loss. Early Human Development, 86(4), 255-260. 

https://doi.org/10.1016/j.earlhumdev.2010.04.002

Wagenmakers, E. J., \& Farrell, S. (2004). AIC model selection using Akaike weights. Psychon Bull Rev, 11(April 2016), 192-196. https://doi.org/10.3758/BF03206482

Walker, E. A., Holte, L., McCreery, R. W., Spratford, M., Page, T., \& Moeller, M. P. (2015). The Influence of Hearing Aid Use on Outcomes of Children With Mild Hearing Loss. J Speech Lang Hear Res, 58(5), 1611-1625. https://doi.org/10.1044/2015_JSLHR-H-15-0043

Walker, E. A., McCreery, R. W., Spratford, M., Oleson, J. J., Van Buren, J., Bentler, R., ... Moeller, M. P. (2015). Trends and Predictors of Longitudinal Hearing Aid Use for Children Who Are Hard of Hearing. Ear Hear, 36(Supl 1), 38S-47S. https://doi.org/10.1097/AUD.0000000000000208

Walker, E. A., Spratford, M., Moeller, M. P., Oleson, J., Ou, H., Roush, P., \& Jacobs, S. (2013). Predictors of Hearing Aid Use Time in Children With Mild-to-Severe Hearing Loss. Language Speech and Hearing Services in Schools, 44(1), 73. https://doi.org/10.1044/0161-1461(2012/12-0005)

Weisleder, A., \& Fernald, A. (2013). Talking to Children Matters: Early Language Experience Strengthens Processing and Builds Vocabulary. Psychol Sci, 24(11), 2143-2152. https://doi.org/10.1177/0956797613488145

Wie, O. B., Falkenberg, E.-S., Tvete, O., \& Tomblin, B. (2007). Children with a cochlear implant: Characteristics and determinants of speech recognition, speech-recognition growth rate, and speech production. Int J Audiol, 46(5), 232-243. https://doi.org/10.1080/14992020601182891

Wiseman, K. B., \& Warner-Czyz, A. D. (2018). Inconsistent device use in pediatric cochlear 
1 implant users: Prevalence and risk factors. Cochlear Implants Int, 19(3), 131-141. https://doi.org/10.1080/14670100.2017.1418161

3 Zauche, L. H., Thul, T. A., Mahoney, A. E. D., \& Stapel-Wax, J. L. (2016). Influence of language

4 nutrition on children's language and cognitive development: An integrated review.

$5 \quad$ Early Child Res Q, Vol. 36, pp. 318-333. https://doi.org/10.1016/j.ecresq.2016.01.015 
$\mathrm{Cl}$ Use

Quiet
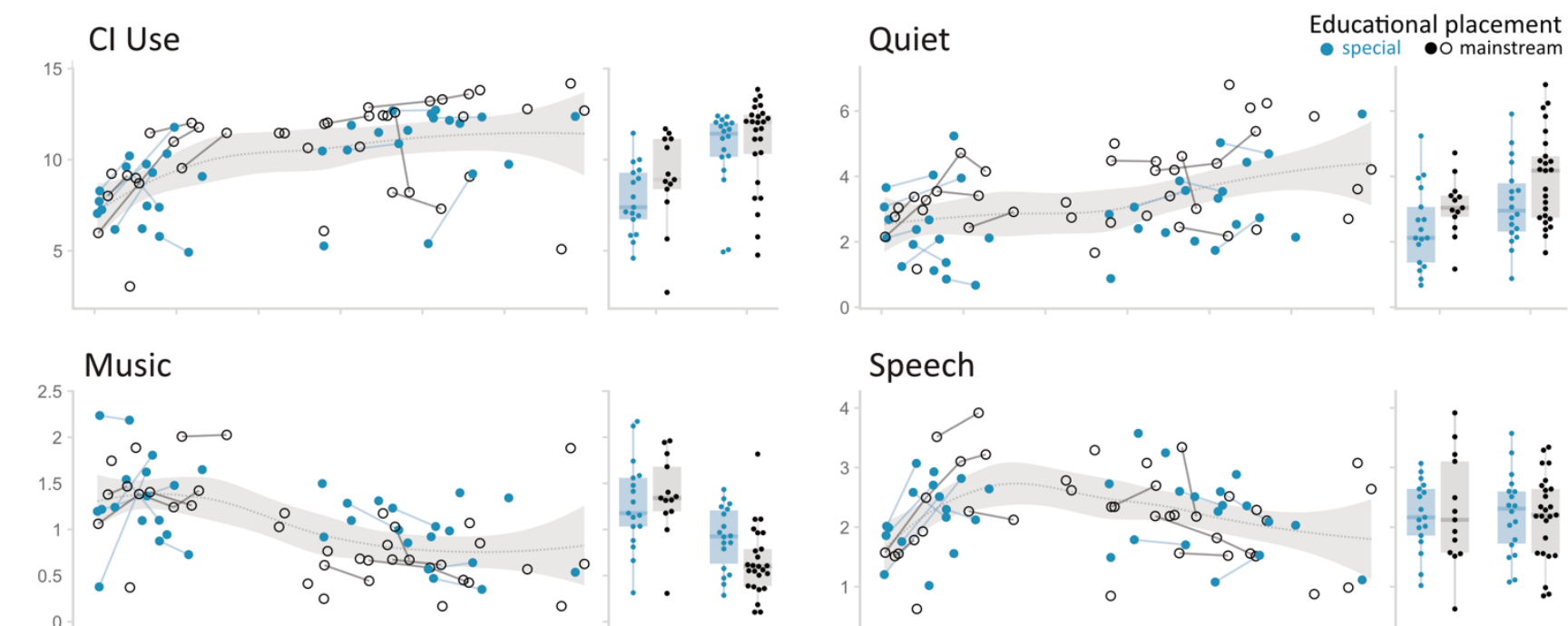

Speech
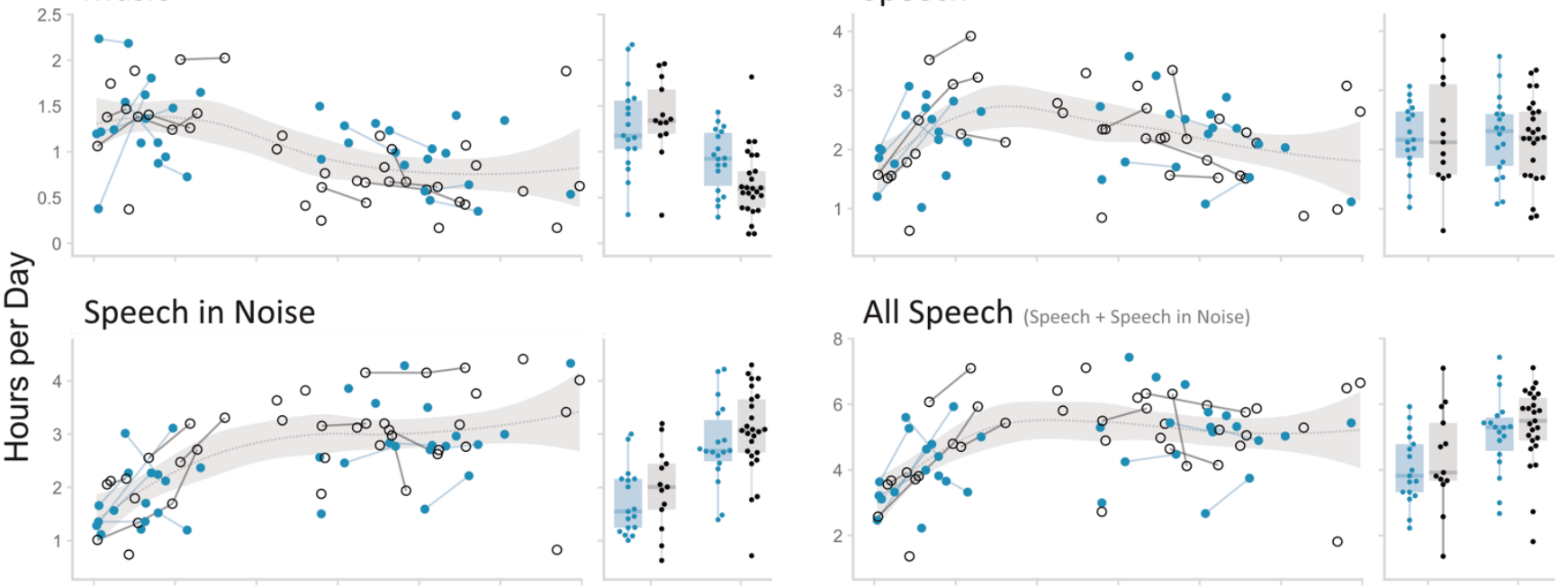

All Speech (speech+ Speech in Noise)

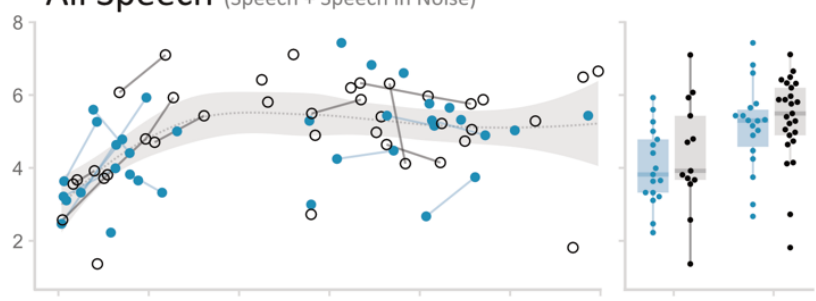

Noise

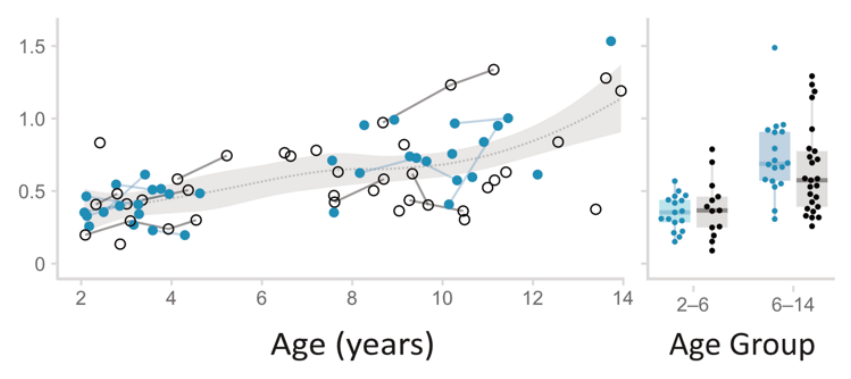

All Noise (Noise + Speech in Noise)

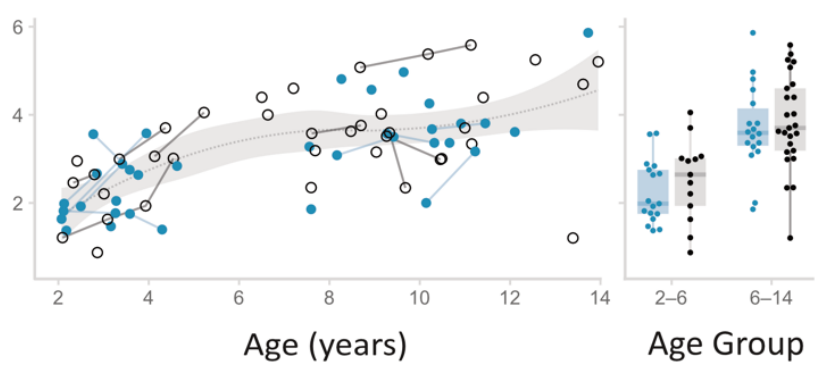

Figure 1. Aggregated data-logging variables for the 12-month time window before each PPVT test moment ( $n=73$ test results from 52 subjects) by chronological age (scatter-plots), age group (boxplots), and educational placement (color). In the scatterplots, PPVT standard scores (SSs) from the same participant are connected by lines; the gray dotted lines and areas in the background show local polynomial regression (LOESS) fits and their 95\% CIs. 
(a)

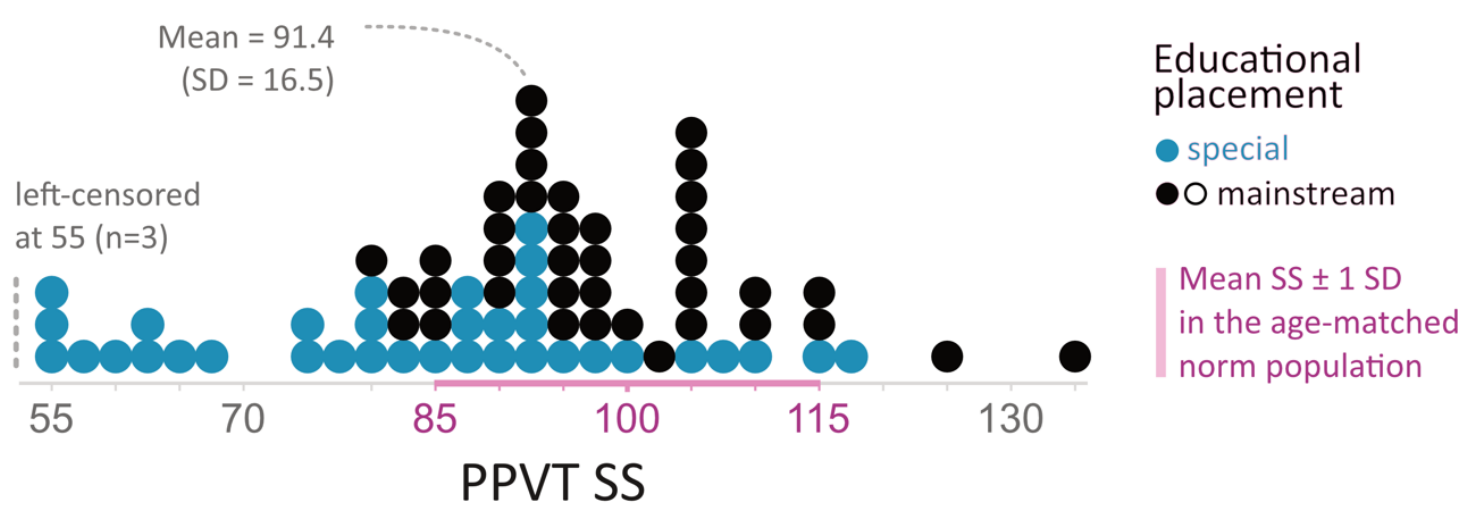

(b)

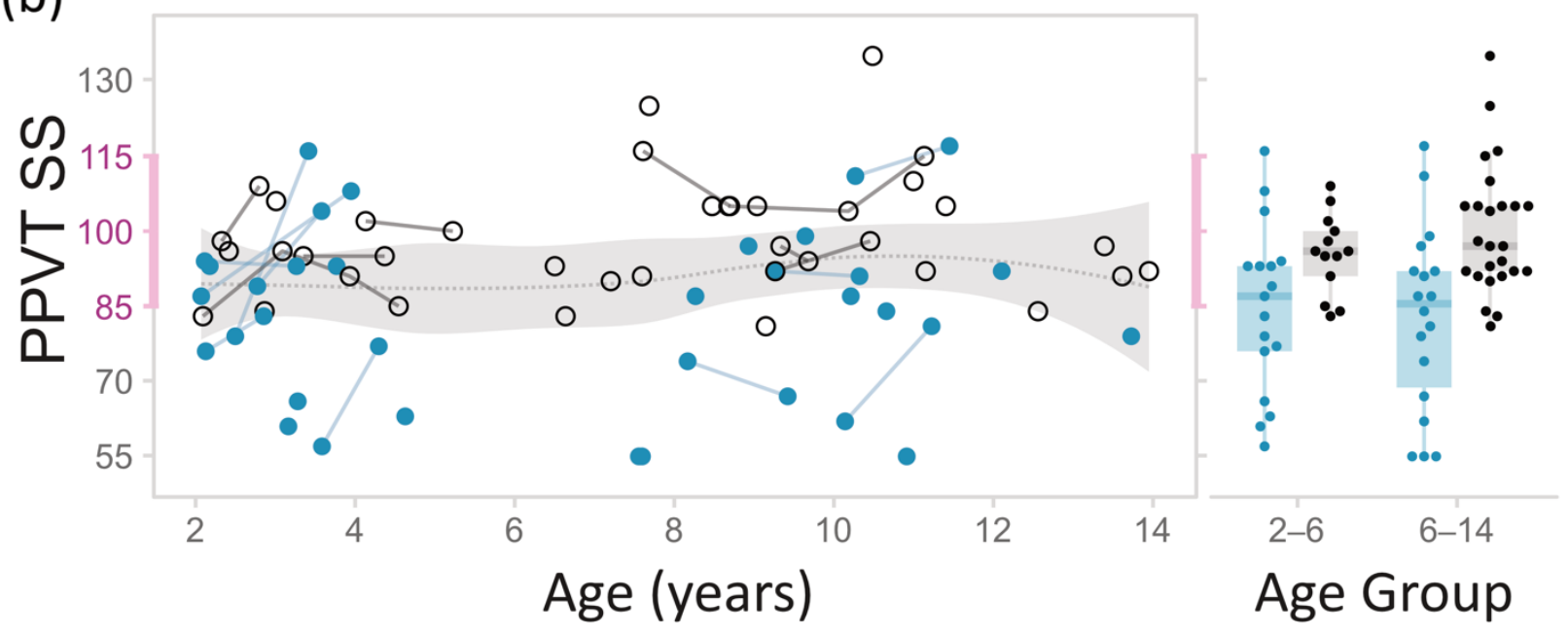

Figure 2. Distribution of the PPVT standard scores (SSs; $n=73$ ) by chronological age and educational placement. (a) Histogram of PPVT SSs. (b) Relation of SSs with age (scatterplot) and age group (boxplot). In the scatterplot, PPVT SSs from the same participant are connected by lines; the gray dotted line and area in the background show a local polynomial regression (LOESS) fit and its 95\% CI. 


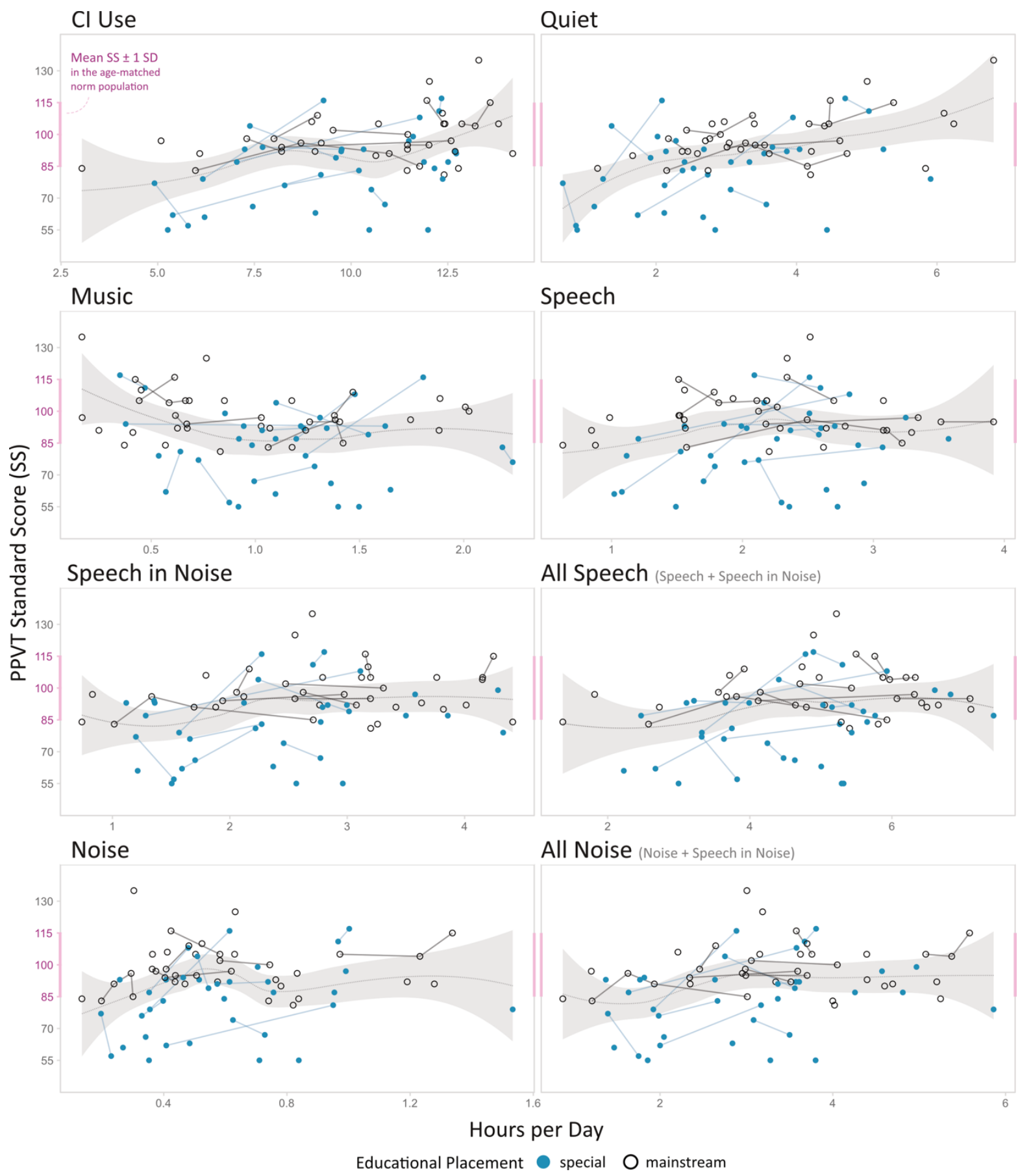

Figure 3. Relation between PPVT standard scores (SSs) and aggregated data-logging variables for the 12 months preceding the PPVT test moment. PPVT SSs from the same participant are connected by lines. The gray dotted lines and areas in the background show local polynomial regression (LOESS) fits and their 95\% CIs. 


\section{Cl Use}

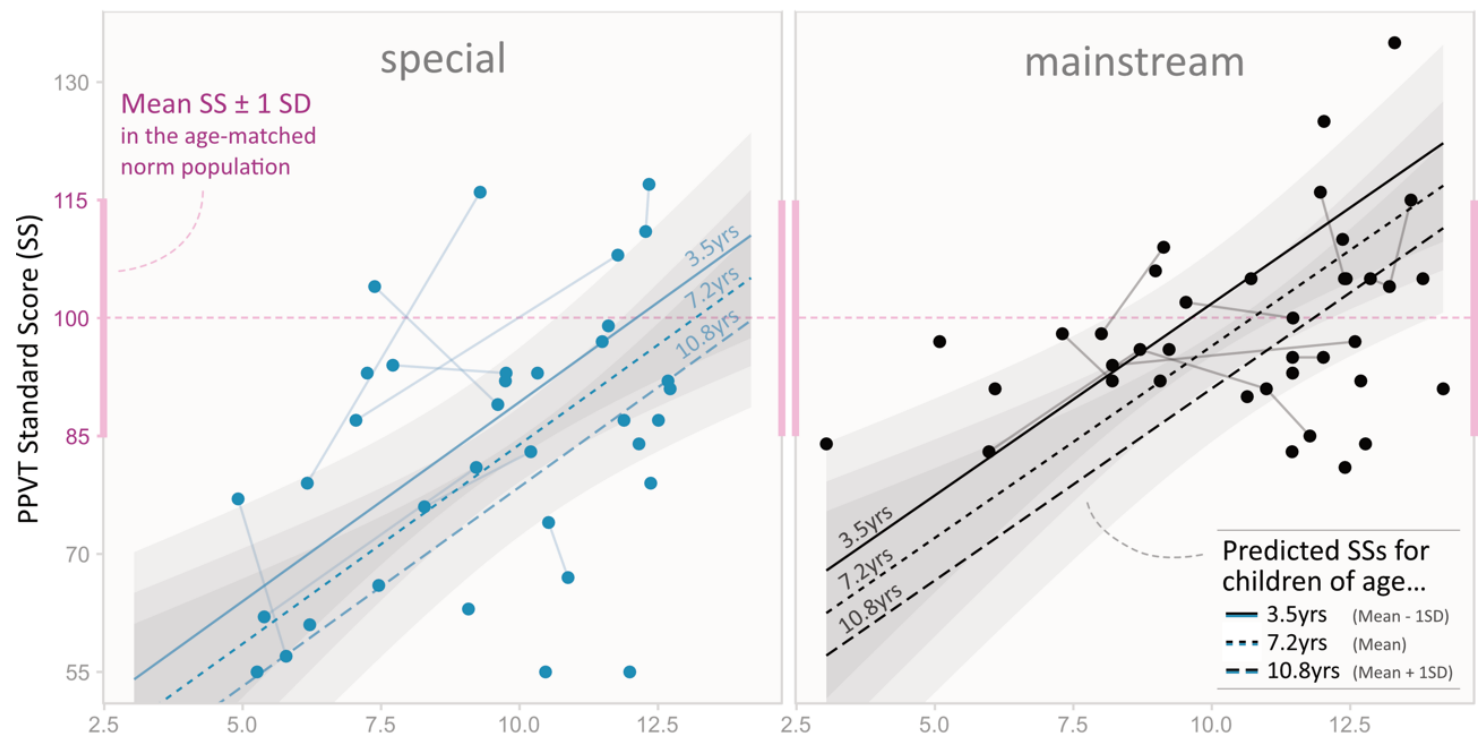

Music

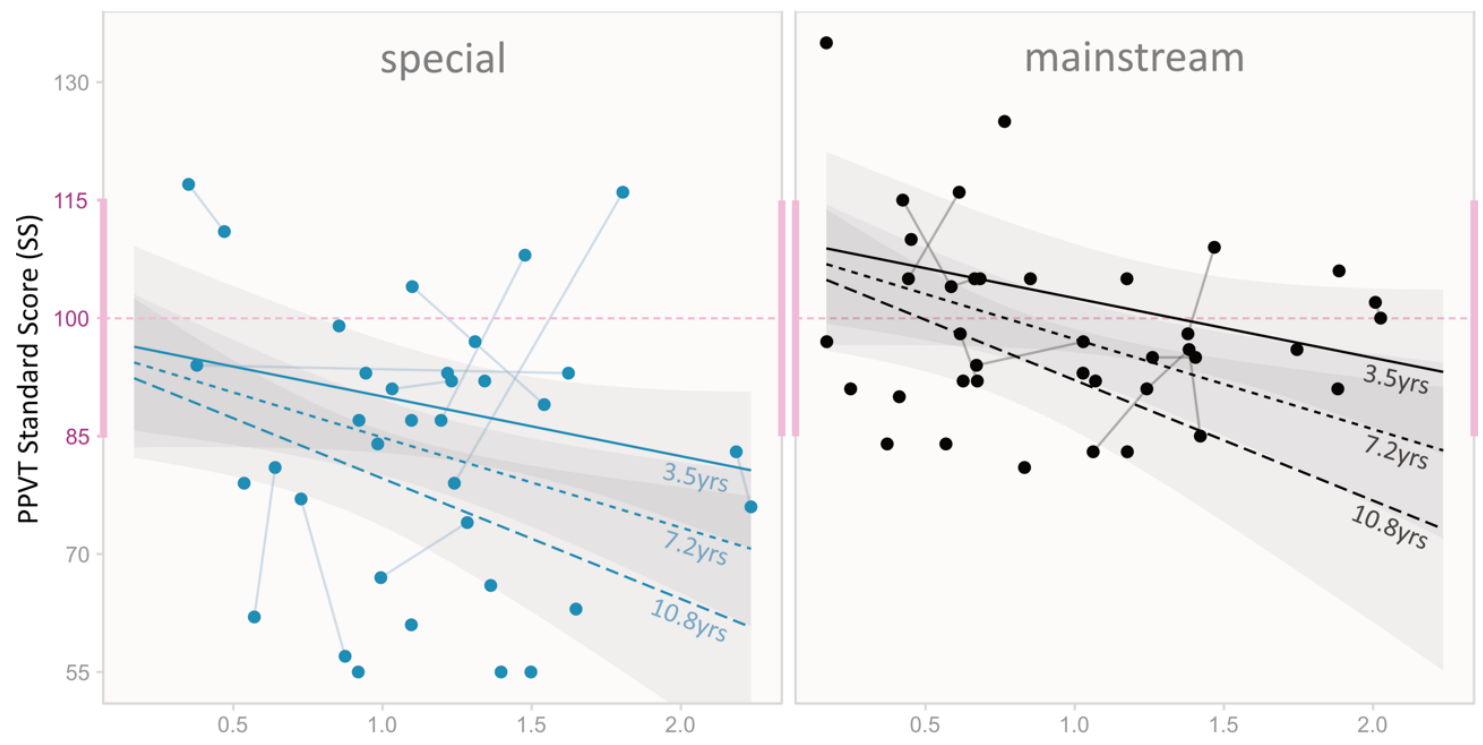

Hours per Day

Figure 4. Raw data and predicted effect of daily CI use (top) and daily exposure to music (bottom) on PPVT standard scores (SSs), by educational placement and for three exemplary ages (corresponding to the sample's mean age $\pm 1 S D$ ). All other predictors are kept at the sample mean. Predictions are based on the model average of the models presented in Table 5. Gray areas show $95 \%$ CI 
Table 1.

Sample characteristics, summary statistics for PPVT results and other variables by educational placement ( $n=73$ PPVT test results from $n=52$ participants).

\begin{tabular}{|c|c|c|c|}
\hline & $\begin{array}{l}\text { Mainstream } \\
\text { Education }\end{array}$ & $\begin{array}{l}\text { Special } \\
\text { Education }{ }^{\ddagger}\end{array}$ & Total \\
\hline $\mathrm{N}$ participants & 27 & 25 & 52 \\
\hline \multicolumn{4}{|l|}{ Gender (n) } \\
\hline Female & 14 & 7 & 21 \\
\hline Male & 13 & 18 & 31 \\
\hline \multicolumn{4}{|l|}{ Etiology $(n)$} \\
\hline Genetic & 10 & 15 & 25 \\
\hline Infection & 6 & 3 & 9 \\
\hline Unknown & 11 & 7 & 18 \\
\hline Age at CI in years, $M$ (SD) & $1.4(0.5)$ & $1.3(0.5)$ & $1.4(0.5)$ \\
\hline \multicolumn{4}{|l|}{ Implantation mode $(n)$} \\
\hline Unilateral & 6 & 10 & 16 \\
\hline Bilateral simultaneous $^{\dagger}$ & 11 & 6 & 17 \\
\hline Bilateral sequential & 10 & 9 & 19 \\
\hline \multicolumn{4}{|l|}{ PPVT results ${ }^{\S}$} \\
\hline $\mathrm{N}$ test results & 38 & 35 & 73 \\
\hline Age at test in years, $M(\mathrm{SD})$ & $7.6(3.6)$ & $6.7(3.7)$ & $7.2(3.6)$ \\
\hline Mean SS (SD) & $98.6(11.6)$ & $83.5(17.5)$ & $91.4(16.5)$ \\
\hline
\end{tabular}

Note: SS = PPVT standard score. ${ }^{\dagger}$ defined as $<1$ y time difference between implantations; $§$ some participants contributed multiple PPVT test results. ₹ One child who had not entered school or daycare at 2.8 years of age was assigned to the special education group. 
Table 2.

Summary statistics for distribution of data-logging variables in average hrs/day, aggregated over the 12-month time window before each PPVT test $(n=73)$.

\begin{tabular}{|c|c|c|c|c|c|c|c|c|c|c|c|c|c|c|c|}
\hline & \multicolumn{5}{|c|}{ Mainstream Education } & \multicolumn{5}{|c|}{ Special Education } & \multicolumn{5}{|c|}{ Total } \\
\hline & \multirow[b]{2}{*}{$M$} & \multirow[b]{2}{*}{ SD } & \multicolumn{3}{|c|}{ Percentile } & \multirow[b]{2}{*}{$M$} & \multirow[b]{2}{*}{ SD } & \multicolumn{3}{|c|}{ Percentile } & \multirow[b]{2}{*}{$M$} & \multirow[b]{2}{*}{ SD } & \multicolumn{3}{|c|}{ Percentile } \\
\hline & & & $25 \%$ & $50 \%$ & $75 \%$ & & & $25 \%$ & $50 \%$ & $75 \%$ & & & $25 \%$ & $50 \%$ & $75 \%$ \\
\hline CI Use & 10.56 & 2.65 & 9.00 & 11.46 & 10.6 & 9.54 & 2.47 & 7.42 & 9.76 & 11.83 & 10.07 & 2.60 & 8.21 & 10.64 & 12.28 \\
\hline Speech & 2.22 & 0.78 & 1.57 & 2.20 & 2.22 & 2.21 & 0.63 & 1.77 & 2.26 & 2.62 & 2.21 & 0.71 & 1.70 & 2.20 & 2.64 \\
\hline Speech in Noise & 2.79 & 0.95 & 2.13 & 2.88 & 2.79 & 2.40 & 0.88 & 1.58 & 2.37 & 2.90 & 2.60 & 0.93 & 1.88 & 2.71 & 3.20 \\
\hline All Speech ${ }^{\dagger}$ & 5.00 & 1.39 & 4.13 & 5.25 & 5.00 & 4.59 & 1.26 & 3.65 & 4.78 & 5.38 & 4.80 & 1.34 & 3.81 & 5.00 & 5.76 \\
\hline Noise & 0.60 & 0.30 & 0.40 & 0.52 & 0.60 & 0.59 & 0.28 & 0.38 & 0.55 & 0.73 & 0.60 & 0.29 & 0.40 & 0.52 & 0.74 \\
\hline All Noise ${ }^{\ddagger}$ & 3.39 & 1.19 & 2.72 & 3.43 & 3.39 & 2.99 & 1.12 & 1.95 & 3.08 & 3.60 & 3.20 & 1.17 & 2.34 & 3.19 & 3.80 \\
\hline Music & 0.96 & 0.52 & 0.59 & 0.84 & 0.96 & 1.15 & 0.45 & 0.90 & 1.10 & 1.38 & 1.05 & 0.50 & 0.64 & 1.03 & 1.38 \\
\hline Quiet & 3.65 & 1.31 & 2.75 & 3.39 & 3.65 & 2.81 & 1.30 & 2.05 & 2.67 & 3.61 & 3.24 & 1.36 & 2.37 & 3.04 & 4.18 \\
\hline Accessory Use ${ }^{\S}$ & 0.42 & 0.58 & 0.00 & 0.03 & 0.42 & 0.46 & 0.74 & 0.00 & 0.00 & 0.86 & 0.44 & 0.66 & 0.00 & 0.01 & 0.81 \\
\hline
\end{tabular}

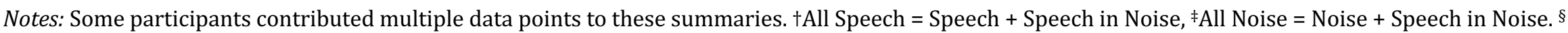
The time using accessories is not counted towards environmental scenes because the Nucleus 6 scene classifier does not categorize sound that is received through an accessory. 
Table 3.

Most parsimonious models predicting PPVT standard scores (SSs) without data-logging variables $(\Delta$ AICc $<2)$. Coefficients, model fit, and average coefficients (full average, with shrinkage).

\begin{tabular}{|c|c|c|c|c|c|c|c|c|c|}
\hline Model & Int & $\mathrm{Edu}$ & Age & Gnd & $\mathrm{k}$ & AICc & $\triangle \mathrm{AICc}$ & AICc-w & $R_{m}^{2}$ \\
\hline 1 & 82.4 & 16.3 & & & 4 & 598.4 & 0 & .57 & .24 \\
\hline 2 & 82.4 & 15.9 & 1.3 & & 5 & 600.2 & 1.86 & .22 & .24 \\
\hline 3 & 84.1 & 15.7 & & -2.4 & 5 & 600.3 & 1.96 & .21 & .25 \\
\hline Avg. & 82.8 & 16.1 & 1.1 & -0.5 & & & & & \\
\hline SE & 3.2 & 3.9 & 1.1 & 2.1 & & & & & \\
\hline Imp. & - & 1 & .22 & .21 & & & & & \\
\hline
\end{tabular}

Notes: All models include a random effect for participant. Age was $z$-standardized. Coefficients larger than two times their $S E$ are bold. Coefficients: Int $=$ Intercept, Edu = educational placement (reference level: special), Gnd = gender (reference level: male). Model fit: $\mathrm{k}=$ number of parameters in the model, AICc = Akaike's information criterion, corrected for sample sizes, AICc-w = AICc-weights (indicate relative support for each model), $R_{m}^{2}=$ coefficient of determination for mixed models. Average Model: Avg. = average coefficient, $\mathrm{SE}=$ Standard Error, Imp. = relative importance. 
Table 4.

Most parsimonious models predicting PPVT standard scores (SSs) with only data-logging variables $(\Delta$ AICc $<2)$. Coefficients, model fit, and average coefficients (full average, with shrinkage).

\begin{tabular}{|c|c|c|c|c|c|c|c|c|c|c|c|c|c|c|c|c|c|c|}
\hline Model & Int & Age & Use & Music & $\begin{array}{l}\text { Agex } \\
\text { Music }\end{array}$ & SpNs & Ns & AllSp & Quiet & $\mathrm{Sp}$ & $\begin{array}{c}\text { Agex } \\
\text { Use }\end{array}$ & $\begin{array}{l}\text { Age } \\
\times \text { Sp }\end{array}$ & $\begin{array}{l}\text { Agex } \\
\text { SpNs }\end{array}$ & $\mathrm{k}$ & AICc & $\triangle \mathrm{AICc}$ & $\begin{array}{c}\text { AICc- } \\
\mathrm{w}\end{array}$ & $R_{m}^{2}$ \\
\hline 1 & 89.1 & -6.0 & 9.6 & -6.9 & -4.0 & & & & & & & & & 7 & 595.4 & 0 & .24 & .32 \\
\hline 2 & 89.2 & -4.9 & 13.2 & -7.2 & -3.8 & -5.0 & & & & & & & & 8 & 595.5 & 0.12 & .22 & .34 \\
\hline 3 & 89.1 & -4.9 & 10.7 & -6.7 & -3.9 & & -2.8 & & & & & & & 8 & 596.5 & 1.19 & .13 & .33 \\
\hline 4 & 89.3 & -6.0 & 12.4 & -6.6 & -3.6 & & & -3.2 & & & & & & 8 & 596.7 & 1.37 & .12 & .33 \\
\hline 5 & 90.7 & & & & & & & & 7.6 & & & & & 4 & 597.1 & 1.76 & .10 & .21 \\
\hline 6 & 90.4 & -6.2 & 11.3 & -7.7 & -5.4 & & & & & -1.0 & -3.7 & 5.1 & & 10 & 597.1 & 1.79 & .10 & .41 \\
\hline 7 & 90.1 & -5.3 & 13.0 & -7.3 & -3.7 & -4.7 & & & & & & & -1.4 & 9 & 597.3 & 1.98 & .09 & .34 \\
\hline Avg. & 89.5 & -5.0 & 10.4 & -6.3 & -3.6 & -1.5 & -0.4 & -0.4 & 0.8 & -0.1 & -0.4 & 0.5 & -0.1 & & & & & \\
\hline SE & 2.1 & 2.9 & 4.5 & 2.9 & 2.0 & 2.9 & 1.3 & 1.5 & 2.4 & 0.8 & 1.3 & 1.6 & 0.6 & & & & & \\
\hline Imp. & - & .9 & .9 & .9 & .9 & .31 & .13 & .12 & .1 & .1 & .1 & .1 & .09 & & & & & \\
\hline
\end{tabular}

Notes: All models included a random effect for participant. All predictors were z-standardized. Coefficients larger than two times their $S E$ are bold. Coefficients: Int = Intercept, SpNs = Speech in Noise, $\mathrm{Sp}=$ Speech, AllSp = All Speech. Model fit: $\mathrm{k}=$ number of parameters in the model, AICc $=$ Akaike's

information criterion, corrected for sample sizes, AICc-w = AICc-weights (indicate relative support for each model), $R_{m}^{2}=$ coefficient of determination for mixed models. Average Model: Avg. = average coefficient, $\mathrm{SE}=$ Standard Error, Imp. = relative importance. 
Table 5.

Most parsimonious models predicting PPVT standard scores (SSs) with a combination of data-logging variables and other variables $(\triangle \mathrm{AICc}<2)$. Coefficients, model fit, and average coefficients (full average, with shrinkage).

\begin{tabular}{|c|c|c|c|c|c|c|c|c|c|c|c|c|c|c|c|c|c|}
\hline Model & Int & Age & Use & Music & Edu & SpNs & $\begin{array}{l}\text { Agex } \\
\text { Music }\end{array}$ & $\begin{array}{l}\text { Edux } \\
\text { SpNs }\end{array}$ & AllSp & $\begin{array}{l}\text { Edux } \\
\text { AllSp }\end{array}$ & $\mathrm{Sp}$ & $\begin{array}{c}\text { Edux } \\
\text { Use }\end{array}$ & $\mathrm{k}$ & AICc & $\triangle \mathrm{AICc}$ & $\begin{array}{c}\text { AICc- } \\
\mathrm{w}\end{array}$ & $R_{m}^{2}$ \\
\hline 1 & 83.9 & -5.3 & 12.8 & -5.9 & 12.5 & -1.7 & -3.0 & -7.0 & & & & & 10 & 583.4 & 0 & .24 & .51 \\
\hline 2 & 84.1 & -6.5 & 12.0 & -5.5 & 11.9 & & -2.6 & & 0.4 & -7.0 & & & 10 & 584.7 & 1.34 & .12 & .50 \\
\hline 3 & 83.9 & -5.2 & 13.2 & -6.2 & 12.4 & & -2.7 & & -4.8 & -7.2 & 4.9 & & 11 & 584.8 & 1.37 & .12 & .51 \\
\hline 4 & 85.0 & -4.9 & 13.0 & -5.3 & 13.3 & -1.9 & & -7.7 & & & & & 9 & 584.8 & 1.42 & .12 & .48 \\
\hline 5 & 83.9 & -5.2 & 13.1 & -6.2 & 12.3 & -6.3 & -2.8 & & 4.4 & -7.3 & & & 11 & 584.9 & 1.48 & .11 & .51 \\
\hline 6 & 85.0 & -6.3 & 12.8 & -4.9 & 12.5 & & & & -0.2 & -7.7 & & & 9 & 585.0 & 1.55 & .11 & .48 \\
\hline 7 & 84.9 & -5.0 & 14.0 & -5.5 & 13.0 & & & & -5.1 & -8.0 & 4.6 & & 10 & 585.3 & 1.92 & .09 & .49 \\
\hline 8 & 83.9 & -5.0 & 15.7 & -5.8 & 12.3 & -5.5 & -2.9 & & & & & -5.5 & 10 & 585.3 & 1.95 & .09 & .49 \\
\hline Avg. & 84.3 & -5.4 & 13.2 & -5.7 & 12.5 & -1.8 & -1.9 & -2.6 & -0.5 & -4.1 & 1.0 & -0.5 & & & & & \\
\hline SE & 2.4 & 2.3 & 3.1 & 2.0 & 3.3 & 3.3 & 1.8 & 3.9 & 3.8 & 4.2 & 2.4 & 1.8 & & & & & \\
\hline Imp. & 1 & 1 & 1 & 1 & .68 & .56 & .56 & .56 & .35 & .21 & .09 & 1 & & & & & \\
\hline
\end{tabular}

Notes: All models included a random effect for participant. Continuous predictors were z-standardized. Coefficients larger than two times their SE are bold. Coefficients: Int = Intercept, Edu = educational placement (reference level: special), SpNs = Speech in Noise, AllSp = All Speech, Sp = Speech. Model fit: $\mathrm{k}=$ number of parameters in the model, AICc = Akaike's information criterion, corrected for sample sizes, AICc- $\mathrm{w}=$ AICc-weights (indicate relative support for each model), $R_{m}^{2}=$ coefficient of determination for mixed models. Average Model: Avg. = average coefficient, $\mathrm{SE}=$ standard error, Imp. = relative importance. 
Supplemental Digital Content 1(Figure S1). Figure that shows the distributions of the data logging variables. pdf

Supplemental Digital Content 2 (Figure S2). Figure that shows the pairwise associations between the data logging variables 
Figure S1. Distribution of Data Logging Variables, aggregated over 12 months before each PPVT test moment $(n=73)$. Solid line and shaded area indicate the Median and central $50 \%$ of the data. Dashed line indicates the position of the Mean. Note that some participants contributed multiple data points.
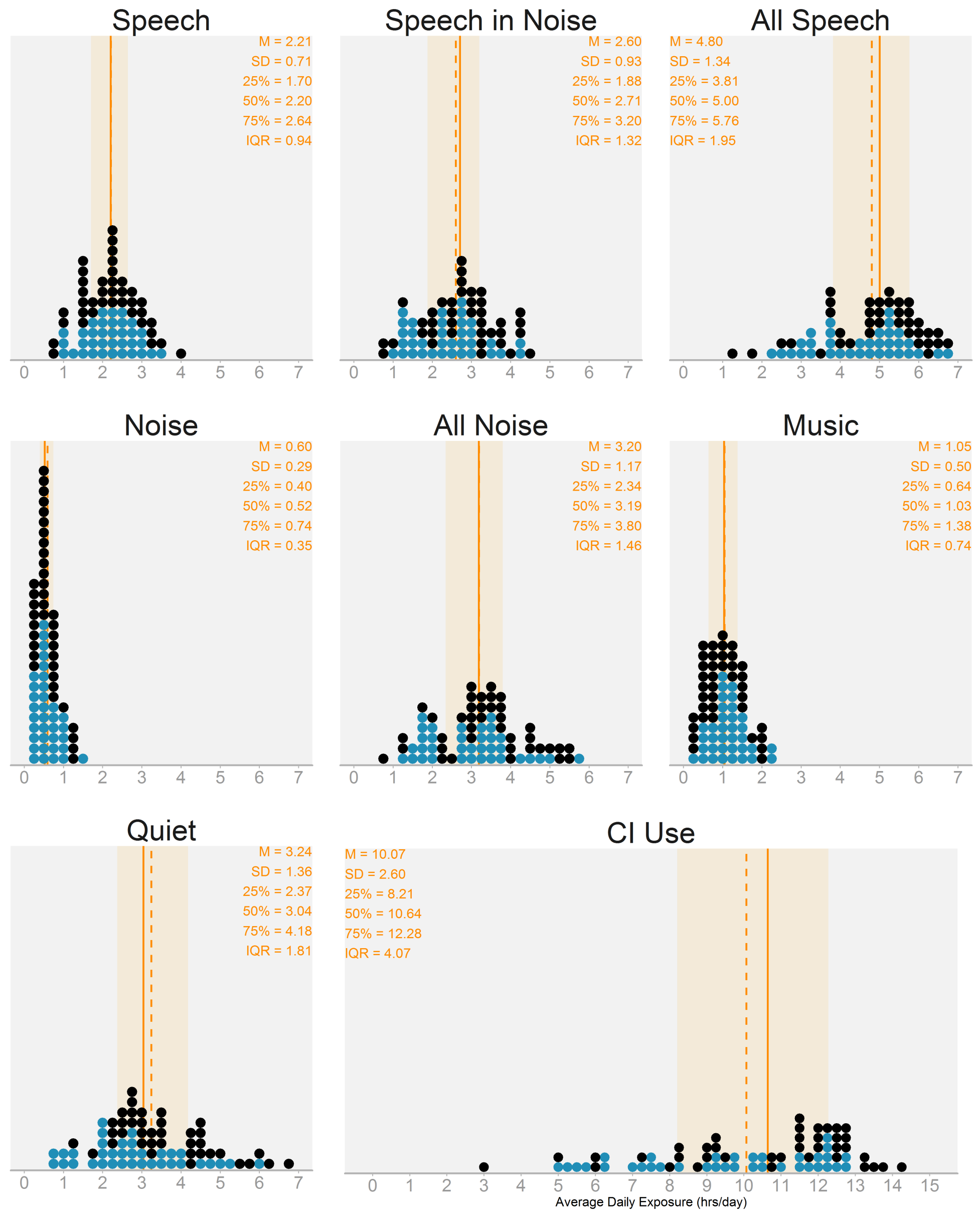
Figure S2. Pairwise Associations between Data Logging Variables, aggregated over 12 months before each PPVT ( $n=73$ PPVT test results of 52 participants). Data points from the same subject are connected by lines. Lines and shaded areas in the background show the predictions and $95 \% \mathrm{Cl}$ from a simple regression with a random intercept for subject. The numbers in the top left corners indicate the corresponding standardized regression coefficients ( $\beta$; pink: $p<.05$, grey: $p \geq .05$ ).

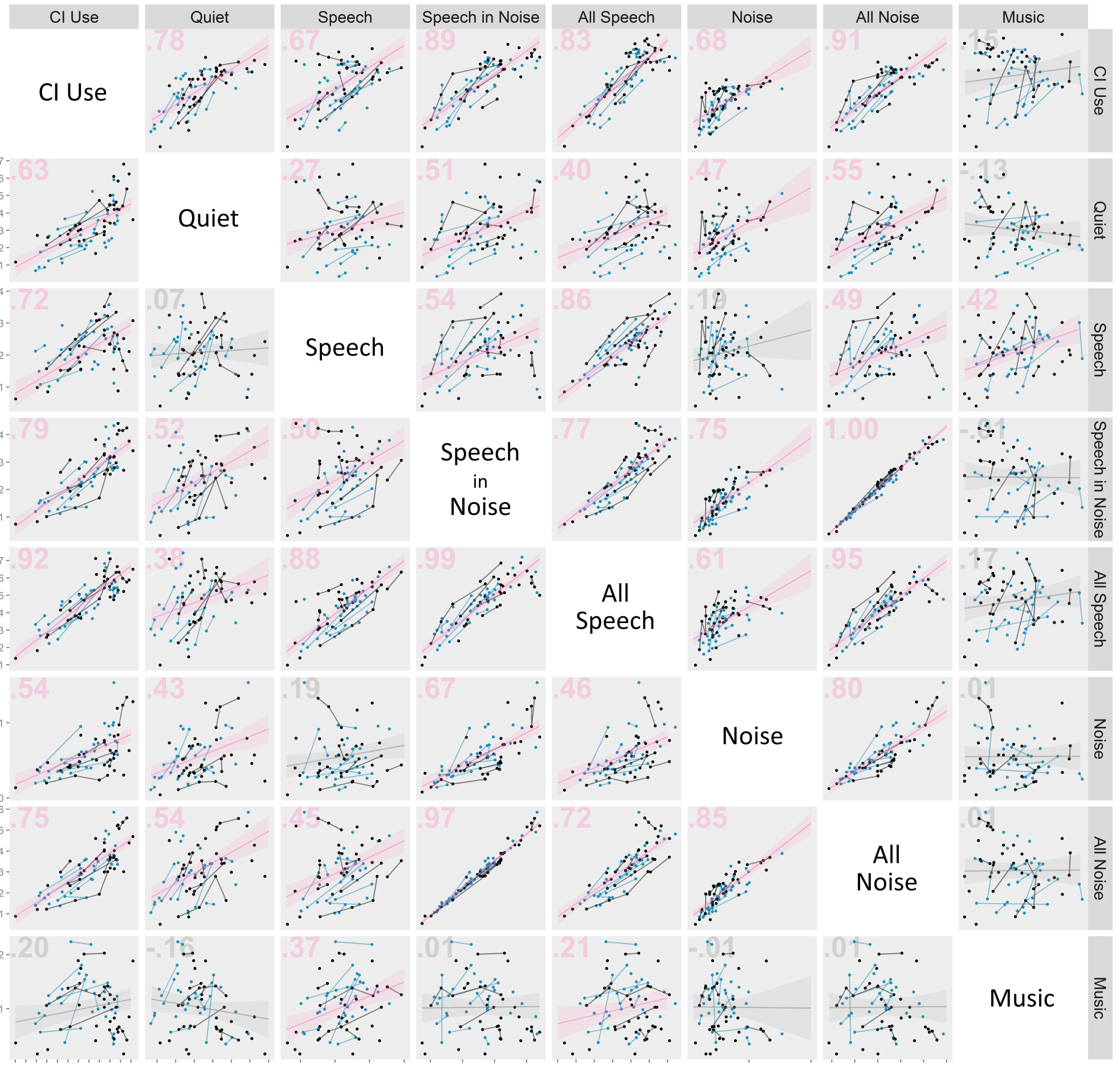

